\title{
In situ multiple sulfur isotope analysis by SIMS of pyrite, chalcopyrite, pyrrhotite, and pentlandite to refine magmatic ore genetic models
}

4 LaFlamme, Crystal $^{\mathrm{a}^{*}}$, Martin, Laure ${ }^{\mathrm{b}}$, Jeon, Heejin ${ }^{\mathrm{b}}$, Reddy, Steven, M. ${ }^{\mathrm{c}}$, Selvaraja,

5 Vikraman ${ }^{\mathrm{a}}$, Caruso, Stefano ${ }^{\mathrm{a}}$, Bui, Thi Hao ${ }^{\mathrm{d}}$, Roberts, Malcolm P. ${ }^{\mathrm{b}}$, Voute, Francois ${ }^{\mathrm{a}}$,

6 Hagemann, Steffen ${ }^{\mathrm{a}}$, Wacey, David ${ }^{\mathrm{b}}$ Littman, Sten $^{\mathrm{e}}$, Wing, Boswell ${ }^{\mathrm{d}}$, Fiorentini, Marco ${ }^{\mathrm{a}}$,

$7 \quad$ Kilburn, Matthew R. ${ }^{\text {b }}$

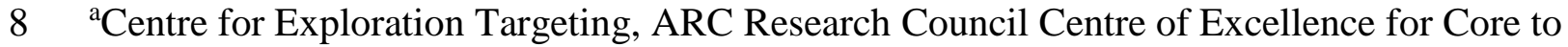

9 Crust Fluid Systems (CCFS), University of Western Australia, Australia

$10{ }^{\mathrm{b} C e n t r e}$ for Microscopy, Characterisation, and Analysis, ARC Centre of Excellence for Core to Crust Fluid Systems (CCFS), University of Western Australia, Australia

${ }^{\mathrm{c}}$ The Institute for Geoscience Research, Department of Applied Geology, Curtin University of Technology, Australia

${ }^{\mathrm{d}}$ Department of Earth and Planetary Sciences and GEOTOP, McGill University, Canada

${ }^{\mathrm{e}}$ Max-Planck-Institut für Marine Mikrobiologie, Bremen, Germany

*corresponding author: crystal.laflamme@uwa.edu.au

\section{ABSTRACT}

With growing interest in the application of in situ multiple sulfur isotope analysis to a variety of mineral systems, we report here the development of a suite of sulfur isotope standards for distribution relevant to magmatic, magmatic-hydrothermal, and hydrothermal ore systems. These materials include Sierra pyrite $\left(\mathrm{FeS}_{2}\right)$, Nifty-b chalcopyrite $\left(\mathrm{CuFeS}_{2}\right)$, Alexo pyrrhotite $\left(\mathrm{Fe}_{(1-\mathrm{x})} \mathrm{S}\right)$, and VMSO pentlandite $\left((\mathrm{Fe}, \mathrm{Ni})_{9} \mathrm{~S}_{8}\right)$ that have been chemically characterized by electron microprobe analysis, isotopically characterized for $\delta^{33} \mathrm{~S}, \delta^{34} \mathrm{~S}$, and $\delta^{36} \mathrm{~S}$ by fluorination gas-source mass spectrometry, and tested for homogeneity at the micro-scale by secondary ion mass spectrometry. Beam-sample interaction as a function of crystallographic orientation is determined to have no effect on $\delta^{34} S$ and $\Delta^{33} S$ isotopic measurements of pentlandite. These new findings provided the basis for a case study on the genesis of the Long-Victor nickel-sulfide deposit located in the world class Kambalda nickel camp in the southern Kalgoorlie Terrane of Western Australia. Results demonstrate that precise multiple sulfur isotope analyses from magmatic pentlandite, pyrrhotite and chalcopyrite can better constrain genetic models related to ore-forming processes. Data indicate that pentlandite, pyrrhotite and chalcopyrite are in isotopic equilibrium and display similar $\Delta^{33} \mathrm{~S}$ values 
1 magmatic assemblage. The three sulfide phases show slightly variable $\delta^{34} \mathrm{~S}$ values

$2 \quad\left(\delta^{34} S_{\text {chalcopyrite }}=2.9 \pm 0.3 \%\right.$ o,$\delta^{34} S_{\text {pentlandite }}=3.1 \pm 0.2 \%$, and $\delta^{34} S_{\text {pyrrhotite }}=3.9 \pm 0.5 \%$, which

3 are indicative of natural fractionation. Careful in situ multiple sulfur isotope analysis of

4 multiple sulfide phases is able to capture the subtle isotopic variability of the magmatic

5 sulfide assemblage, which may help resolve the nature of the ore-forming process. Hence,

6 this SIMS-based approach discriminates the magmatic sulfur isotope signature from that

7 recorded in metamorphic- and alteration-related sulfides, which is not resolved during bulk

8 rock fluorination analysis. The results indicate that, unlike the giant dunite-hosted komatiite

9 systems that thermo-mechanically assimilated volcanogenic massive sulfides proximal to

10 vents and display negative $\Delta^{33} \mathrm{~S}$ values, the Kambalda ores formed in relatively distal

11 environments assimilating abyssal sulfidic shales.

12

\section{HIGHLIGHTS}

- Characterisation of four sulfide standards for multiple sulfur isotope analysis: pyrite, chalcopyrite, pyrrhotite, and pentlandite for distribution

- Analysis of orientation effect in pentlandite

- Natural sulfur isotope fractionation between pentlandite and pyrrhotite

- Case study multiple sulfur isotope analysis of three sulfide phases within world-class Long-Victor komatiite-hosted nickel-sulfide deposit

\section{KEYWORDS}

Multiple sulfur isotopes, SIMS, in situ, sulfide minerals, ore genesis

\section{INTRODUCTION}

Sulfur is a trace element in silicate melts, typically concentrated below $0.2 \mathrm{wt} \%$. However, it is an essential element in a wide range of environments including the lithosphere, biosphere, hydrosphere, and atmosphere. In recent years, our understanding of the sulfur cycle and its role in the evolution of these terrestrial reservoirs has been revolutionised by the study of the sulfur isotope composition of pyrite, the most common sulfide mineral (Farquhar et al., 2000; Kump, 2012 and references therein; Strauss, 1997; Thomassot et al., 2015). We have gained a fundamental understanding into the development of early Earth's processes, in particular those linked to the emergence of life and the development of an oxygenated atmosphere (Farquhar et al., 2000), by the discovery of mass independent fractionation (MIF) of sulfur 34 isotopes.

Sulfur resides in the Earth's mantle, crust and hydrosphere but is locally concentrated in mineralised systems typically associated with ore deposits, where it acts as the primary complexing ligand in the formation of sulfide minerals. Mantle- and crustally-derived magmas have brought large quantities of economic metals from the Earth's interior to the 
1 near surface, and hydrothermal fluids have remobilised and re-precipitated these metals within the crust as different sulfides. The sulfur itself may be sourced from a variety of compositional reservoirs, each with distinct isotopic compositions. Mixing and interactions with the mantle, crustal magmas, hydrothermal fluids, country rocks, or meteoric waters imparts specific isotopic signatures, resulting in minerals with a range of isotopic compositions. As such, intra-grain and inter-grain chemical and isotopic variations in sulfurrich mineralised systems record the interaction of these different reservoirs and offer unique insights into the complex fluid-rock interactions within mineral systems (McCuaig et al. 2010). For example, in magmatic ore deposits, sulfur isotope data have fingerprinted the source of the sulfur linked to ore genesis (Bekker et al., 2009; Chang et al., 2008; Fiorentini et al., 2012a; Hiebert et al., 2013; Lesher and Groves, 1986; Penniston-Dorland et al., 2008; Sharman et al., 2013) and constrained the geodynamic framework where these deposits formed (e.g., Chen et al., 2015; Fiorentini et al., 2012b; Giacometti et al., 2014). Similarly, sulfur isotope studies have proven to be vital in characterising magmatic-hydrothermal (Helt et al., 2014; Xue et al., 2013) and hydrothermal systems (e.g., Jamieson et al., 2013; Leach et al., 2005; Sharman et al., 2015). Constraining the sulfur isotopic signature in magmatichydrothermal mineral systems is useful in delineating the source of sulfur, and is an important parameter to understand how, when and where sulfur saturation occurs (e.g., Evans et al., 2014). In addition, such data provides a better understanding of the geodynamic environment in which the mineralising process occurs which impacts on the targeting rationale applied during exploration (e.g., Fiorentini et al., 2012a). Consequently, ore deposits are a perfect laboratory for understanding the source and mobility of sulfur in a wide variety of settings.

Mineral systems and ore deposits have characteristically complex microscale intra-granular and inter-granular textures due to variations in their chemistry during formation and subsequent re-equilibration during cooling (e.g., pentlandite exsolution in pyrrhotite; Durazzo and Taylor, 1982). In situ sulfur isotope analysis at the microscale has the potential to revolutionise our understanding of ore forming processes. The development of in situ analytical techniques using laser ablation-(multi-collection)-inductively coupled plasma mass spectrometry (LA-MC-ICPMS; see Bühn et al., 2012; Craddock et al., 2008) and large geometry secondary ion mass spectrometry (SIMS; see Farquhar et al., 2013; Ireland et al., 2014; Ushikubo et al., 2014; Whitehouse, 2013) now allows high-precision isotopic analysis of multiple sulfur isotopes with spot sizes nearing ten microns. The ultra-high sensitivity of SIMS in particular affords the ability to measure the least common stable isotopes of sulfur, ${ }^{33} \mathrm{~S}(0.75 \%)$ and ${ }^{36} \mathrm{~S}(0.02 \%)$, together with the more abundant ${ }^{32} \mathrm{~S}(95.02 \%)$ and ${ }^{34} \mathrm{~S}(4.21 \%)$ isotopes, simultaneously from the same volume of material. This gives the potential to identify the anomalous sulfur isotopic signatures indicative of mass independent fractionation (MIF; $\Delta^{33} \mathrm{~S}$ and $\Delta^{36} \mathrm{~S}$ ) together with $\delta^{34} \mathrm{~S}$.

Instrumental mass fractionation in SIMS is intrinsically linked to the composition and crystallographic orientation of the material being analysed and the specific conditions under which the analysis is performed. Therefore, accurate isotopic measurements require careful 
2008). Although a number of reference materials have been developed for acquiring in situ 2sulfur isotopes (e.g., Kozdon et al., 2010), the majority of published in situ 3- or 4-sulfur isotope analyses have been acquired from the most common sulfide mineral, pyrite. As such, many SIMS laboratories worldwide have developed "in-house" pyrite (and to a lesser degree other) standards for multiple sulfur isotope analysis (Balmat, Isua 248474, Ruttan; see Whitehouse, 2013; Ushikubo et al., 2014; Hauri et al., 2016). With growing interest in the application of in situ sulfur isotope analysis to a wide variety range of mineral systems, there presently remain scarce. In addition to composition, sulfide crystallography has previously been demonstrated to potentially create an orientation effect-induced instrumental mass bias on sulfur isotope analysis for certain sulfides including galena $(\mathrm{PbS})$ and sphalerite $((\mathrm{Zn}, \mathrm{Fe}) \mathrm{S})$ but not others including pyrite $\left(\mathrm{FeS}_{2}\right)$, pyrrhotite $(\mathrm{Fe}(1-\mathrm{x}) \mathrm{S})$, and chalcopyrite $\left(\mathrm{CuFeS}_{2}\right)$ (Kozdon et al., 2010; Kita et al., 2011). Of these sulfides, most have a diamondcubic crystal structure, with the exception of galena which has a cubic hexoctahedral structure. Here, we build on this observation to demonstrate that orientation effect does not induce instrumental mass fractionation on $\delta^{34} S$ and $\Delta^{33} S$ in another cubic hexoctahedral sulfide - pentlandite $\left((\mathrm{Fe}, \mathrm{Ni})_{9} \mathrm{~S}_{8}\right)$.

Deviations from mass dependent fractionation are typically (but not uniquely) triggered by the presence of an oxygen-poor atmosphere that existed before the Great Oxidation Event at ca. 2.4 Ga in which ultraviolet radiation was the driver for mass independent photochemical separation of sulfur isotopes (e.g., Farquhar et al., 2000; Farquhar and Wing, 2003). For this reason, the measure of ${ }^{33} \mathrm{~S}$ has become essential to evaluate the full suite of isotopic features of Archean rocks (e.g., Bühn et al., 2012; Farquhar et al., 2013), and those from younger terranes that might be sourcing Archean rocks (e.g., Cabral et al., 2013; Selvaraja et al., in submission). The least abundant stable isotope of sulfur, ${ }^{36} \mathrm{~S}$, behaves similarly to ${ }^{33} \mathrm{~S}$, and has also become increasingly important for fingerprinting Archean source rocks and understanding early Earth processes. The $\Delta^{36} \mathrm{~S} / \Delta^{33} \mathrm{~S}$ ratio can elucidate between mass dependent processes and contributions from Archean MIF sources when magnitudes of mass dependent fractionation deviations are small (Farquhar et al., 2007; Johnston, 2011).

We present multiple sulfur isotope data from pentlandite, pyrrhotite, and chalcopyrite from an Archean komatiitic massive nickel-sulfide deposit. To do so, we have developed four reference materials (pyrite, chalcopyrite, pyrrhotite, and pentlandite) that we have fully chemically and isotopically characterized for multiple sulfur isotope analysis. We present multiple sulfur isotope results from multiple sulfides within the deposit to constrain the source of the sulfur that triggered sulfide saturation and investigate the geodynamic setting in which this magmatic system was emplaced.

\section{METHODS}

To determine the chemical and isotope composition of potential sulfide reference materials we combined three analytical techniques. Firstly, we performed wavelength dispersive spectrometry (WDS) by electron probe micro-analysis (EPMA) on a multitude of grains (or grain fragments) of each candidate reference material to ensure that the reference material is 
1 chemically homogeneous across a number of grains (or grain fragments). Chemical compositions (spot analyses) were linked to chemical WDS maps and scanning electron microscope backscatter electron (SEM-BSE) images to highlight potential chemical zonation, mineralogical inclusions, and fractures. Details of SEM-BSE and EPMA-WDS are presented in the Supplementary Material.

Secondly, at least five grains (or grain fragments) of each candidate reference material were analysed for in situ multiple sulfur isotopes by SIMS to determine whether an adequate level

of reproducibility exists at the intra- and inter-grain scale (isotopic homogeneity). M
materials were tested prior to selecting the material that displayed adequate isotopic homogeneity (reproducibility on ${ }^{34} \mathrm{~S} /{ }^{32} \mathrm{~S}$ better than $0.5 \%$ ). For instance, five materials from different environments were tested to find a suitable chalcopyrite standard (see section 5.1 for discussion on selecting sulfide reference material). To further determine on what scale sufficient homogeneity existed once the reference material was selected, more than 40 grains for each material were analysed. If the reference material was deemed suitable, multiple grains or grain fragments (in the case of material derived from large crystals) were analysed by bulk multiple sulfur analyses. Bulk analyses were completed by fluorination gas-source mass spectrometry. In each case, sulfur was extracted from 5 to 11 separate aliquots (of extracted sulfur from separate grains or grain fragments) and analysed for its multiple sulfur isotopic composition. We further evaluated the homogeneity of the SIMS material by completing an MSWD test on the data after Wing and Farquhar, (2015). The respective analytical techniques are described in detail below.

For the case study, we investigated the chemical composition and multiple sulfur isotope signature of three phases (pentlandite, pyrrhotite, chalcopyrite). A micro-X-ray Fluorescence (XRF) elemental map was acquired to visually investigate the textural relationship between the three sulfide phases and choose samples for in situ and bulk isotope analyses (details regarding analytical set up are presented in the Supplementary Materials). EPMA analyses on pyrrhotite and pentlandite were completed to ensure a similar chemical composition to the reference materials (see Appendix A). In situ isotope signatures of pentlandite, pyrrhotite and chalcopyrite were compared to ten bulk rock fluorination values that incorporated all the coexisting sulfide phases (see Appendix B and C). We also used the case study material to assess the crystallographic orientation effect in pentlandite. To do so, Electron Backscatter Diffraction Analysis (EBSD) was completed on this sample and pentlandite crystal orientation was compared with multiple sulfur isotope results.

\subsection{Secondary Ion Mass Spectrometry}

\subsubsection{Analytical set up and conditions}

In situ sulfur isotopic ratios were measured using a CAMECA IMS1280 large-geometry ion microprobe at the CMCA, UWA. Sample mounts were made by coring $3 \mathrm{~mm}$ diameter pucks from rock fragments using a drill press fitted with diamond drill bits, then mounted and cast in the central portion of a $25 \mathrm{~mm}$ in diameter epoxy mount. Standard blocks (cast separately to be reused) were made by mounting 1-2 grain fragments of pyrite chalcopyrite and $1 \mathrm{~mm}$ diameter pucks of rock fragments host to pyrrhotite and pentlandite. Reference materials 
were cast in epoxy $\sim 8 \mathrm{~mm}$ from the edge of a mount. Sample mounts and standard blocks were trimmed to a thickness of $5 \mathrm{~mm}$ using a precision saw, coated with $30 \mathrm{~nm}$ of gold, and mounted together (after being appropriately trimmed) in the sample holder (further details provided in the Supplementary Materials). Care was taken to set the surfaces of the standard and sample blocks at the same level in the sample holder. If necessary, a small amount of carbon paint was applied to provide good conductivity between both pieces. To ensure that results are not a product of analytical artefacts due to $\mathrm{X}-\mathrm{Y}-\mathrm{Z}$ positioning, a reference material is also mounted and cast with the sample block to compare with values generated from the standard block. Additional details regarding sample preparation for SIMS analysis are presented in the Supplementary Materials.

The ion microprobe was operated in multicollection mode using a $\mathrm{Cs}^{+}$primary beam with an intensity of 1-4 nA in Gaussian mode that interacted with the sample at $20 \mathrm{keV}$. In some instances, depending on the nature of the sample (i.e., size of sulfides, surrounding material, whether sulfides are mounted as individual grains or incorporated in rock chips) a normal incidence electron flood gun was used for charge compensation. Following a $30 \mathrm{~s}$ pre-sputter, secondary sulfur ions from the target sample were extracted at $-10 \mathrm{kV}$ and admitted to the mass spectrometer with a field magnification of $133 \times$, with automated centering of the secondary beam in the field/aperture (both $\mathrm{x}$ and $\mathrm{y}$; aperture size $4000 \mu \mathrm{m}$ ) and entrance slit (x direction only; slit width $60 \mu \mathrm{m}$ or $90 \mu \mathrm{m}$ in some cases). The NMR magnetic field controller locked the axial mass at the beginning of each session, and the mass spectrometer operated at a mass resolution $(\mathrm{M} / \Delta \mathrm{M}$ ) of about 2500 (exit slit width of $500 \mu \mathrm{m}$ on the multicollector). Under these conditions, the hydrite interference ${ }^{32} \mathrm{~S}^{1} \mathrm{H}$ on the ${ }^{33} \mathrm{~S}$ peak was avoided by offsetting the ${ }^{33} \mathrm{~S}$ peak centre to the low mass side.

For triple sulfur isotope measurements $\left({ }^{32} \mathrm{~S},{ }^{33} \mathrm{~S}\right.$ and $\left.{ }^{34} \mathrm{~S}\right)$, a $15 \mu \mathrm{m}$ raster was applied, and the sulfur isotopes were simultaneously detected by three Faraday Cups using amplifiers with $10^{10} \Omega$ (L'2), $10^{11} \Omega$ (L1), and $10^{11} \Omega$ (FC2 or H1) resistors. Data were collected over $123 \mathrm{~s}$ of acquisition time in 20 integration cycles. Count rates on ${ }^{32} \mathrm{~S}$ varied from $1 \times 10^{9}$ to $3.5 \times 10^{9}$ cps on pyrite, depending on the intensity of the primary beam but is typically $2.2-2.4 \times 10^{9} \mathrm{cps}$ with a $2.5 \mathrm{nA}$ primary beam.

Quadruple sulfur isotope $\left({ }^{32} \mathrm{~S},{ }^{33} \mathrm{~S},{ }^{34} \mathrm{~S}\right.$, and $\left.{ }^{36} \mathrm{~S}\right)$ analysis has different analytical protocols to include the measurement of ${ }^{36} \mathrm{~S}$ using a low-noise ion counting electron multiplier (EM) in the $\mathrm{H} 2$ position of the multicollector axis. A higher primary beam current (3-4 nA), larger raster (30 $\mu \mathrm{m}$ for pre-sputter and $20 \mu \mathrm{m}$ for analysis) and longer acquisition time ( $279 \mathrm{~s}$ in 45 integration cycles) were necessary to achieve adequate repeatability on ${ }^{36} \mathrm{~S}$. The count rates on ${ }^{36} \mathrm{~S}$ of typically $2-4 \times 10^{5} \mathrm{cps}$ for pyrite cause a significant gain drift for the EM. Hence, the EM high voltage was optimised using a Pulse Height Amplitude (PHA) distribution curve at the start of each session, and the gain drift was measured three times during each analysis (at the beginning, middle and end) and corrected by the CAMECA CIPS software (see Schuhmacher et al., 2004). In the case of unknown material, measurements were interspersed with matrix-matched reference material to calibrate isotope ratios and monitor internal sample repeatability. 


\subsubsection{Data processing and error propagation}

3 In situ sulfur isotope measurements by SIMS are corrected in two steps. Firstly, the pyrite standard (Sierra; see section 3.1) is analysed once every five to eight analyses, regardless of whether the pyrite is being used as the primary standard for that particular session, allowing for the assessment of the stability of the instrument during the given analytical session, and correct for instrumental drift. Secondly, sample isotopic ratios are corrected for instrumental mass fractionation using the correction factor $\alpha$, determined by normalising the mean of all measurements on the matrix matched reference material, $R_{\text {std }}$, to the isotopic ratio of the reference material $\mathrm{R}_{\mathrm{RM}}$ as obtained by independent bulk methods (e.g. fluorination gas-source 11 mass spectrometry):

$$
\text { (1) } \quad \alpha=\frac{\mathrm{R}_{\mathrm{std}}}{\mathrm{R}_{\mathrm{RM}}}
$$

13 The propagated uncertainty for the $\delta^{\mathrm{x}} \mathrm{S}$ value of each sample spot takes into account the 14 internal error on the raw isotopic ratios, the uncertainty on the drift correction where 15 necessary and the uncertainty on the standard measurement, calculated as the standard 16 deviation on the mean isotopic ratios measured in the standards.

Identifying MIF has become increasingly important in assessing a number of geological environments because it reveals fundamental information pertaining to the age and source of sulfide mineralization (e.g., Johnston, 2011). MIF is presented as $\Delta^{33} \mathrm{~S}$ and $\Delta^{36} \mathrm{~S}$ to quantify the deviation from the mass dependant fractionation slope; however, these values can be small in magnitude - often much less than $1.0 \%$ (see Figure 1). Therefore, it is important to systematically quantify uncertainty on these values to ascertain whether a MIF signature does 24 indeed exist.

The mass independent relationship is denoted by the $\Delta^{33} \mathrm{~S}$ and $\Delta^{36} \mathrm{~S}$ notation to represent the deviation between the isotopic ratios measured and those predicted according to mass

28 dependent fractionation, and is defined as:

$$
\text { (2) } \Delta^{\mathrm{x}} \mathrm{S}_{i}=\delta^{\mathrm{x}} \mathrm{S}_{i}-1000 \times\left[\left(\frac{\delta^{34} \mathrm{~S}_{\mathrm{V}-\mathrm{CDT}}}{1000}+1\right)^{\lambda}-1\right]
$$

where $\mathrm{x}$ is either 33 or 36 and $\lambda$ is the slope of the mass dependent fractionation line $(0.515$ for $\delta^{33} \mathrm{~S}$ and 1.91 for $\delta^{36} \mathrm{~S}$; Hulston and Thode, 1965; Ono et al., 2006a). The $\lambda$ values approximate the relationships for high temperature equilibrium isotopic fractionations 33 (Farquhar and Wing, 2003). 


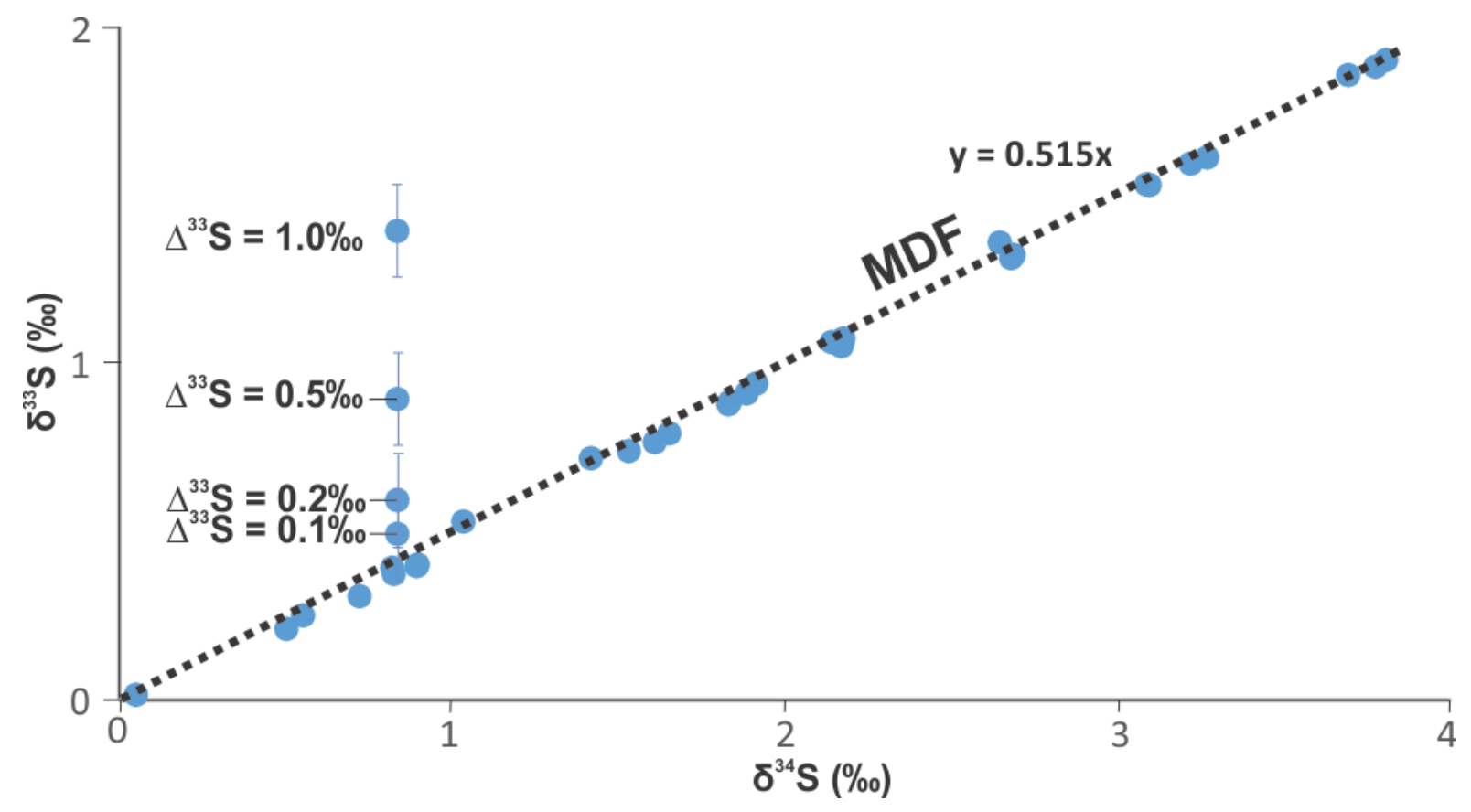

1

8 The uncertainty on $\Delta^{33} \mathrm{~S}$ and $\Delta^{36} \mathrm{~S}$ is calculated by propagating the uncertainties on $\delta^{33} \mathrm{~S}, \delta^{34} \mathrm{~S}$, 9

Figure 1: Calculated magnitudes of mass independent fractionation as deviations from the mass dependent fractionation line (MDF) presented in $\delta^{33} \mathrm{~S}$ vs. $\delta^{34} \mathrm{~S}$ space. The small deviations from the MDF line represent mass independent fractionation. This highlights the importance of: 1) precise and accurate multiple sulfur isotope measurements, and 2) quantification of uncertainty on $\Delta^{33} \mathrm{~S}$. Although not expressed in this figure, quantifying $\Delta^{36} \mathrm{~S}$ is equally important. and $\delta^{36} \mathrm{~S}$; however, paired sulfur isotope ratios covary in $\delta^{33} \mathrm{~S}-\delta^{34} \mathrm{~S}$ and $\delta^{36} \mathrm{~S}-\delta^{34} \mathrm{~S}$ space. To account for this relationship, we determined the covariance on the reference material of the analytical session and propagated to the measurements of $\delta^{33} S$ and $\delta^{34} S\left(\sigma_{\delta^{34} S \delta^{33} S}\right)$ and $\delta^{36} S$

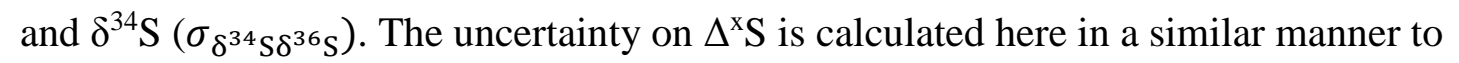
Farquhar et al. (2013) but also accounts for this covariance in the formulation of the uncertainties on $\Delta^{33} \mathrm{~S}$ and $\Delta^{36} \mathrm{~S}$ as follows:

$$
\text { (3) } \sigma_{\Delta^{\mathrm{x} S}}=\sqrt{\frac{\sigma_{\delta^{\mathrm{x} S}}^{2}+\sigma_{\delta^{34} \mathrm{~S}}^{2} \times\left[\lambda \times\left(1+\frac{\delta^{34} \mathrm{~S}}{1000}\right)^{-(1-\lambda)} \times \sigma_{\delta^{34} S}^{2}\right]^{2}+2 \times \sigma_{\delta^{34} S \delta^{\mathrm{x} S}} \times}{\left[\lambda \times\left(1+\frac{\delta^{34} S}{1000}\right)^{-(1-\lambda)}\right]}}
$$

where variables are as in equation 2.

\subsection{Fluorination gas-source mass spectrometry}

Samples for fluorination coupled with gas-source mass spectrometry were analysed at the Stable Isotope Laboratory of the Department of Earth and Planetary Sciences at McGill University, Montreal, Canada. Sulfide-bearing samples were microdrilled using a $1 \mathrm{~mm}$ 
1 diameter hand drill. Each sample was microdrilled multiple times. Sulfur was chemically extracted from the 15-30 mg powders to form silver sulfide by chromium reduction as described by Canfield et al. (1986). Silver sulfide was fluorinated at $225^{\circ} \mathrm{C}$ in a $\mathrm{Ni}$ bomb under $\mathrm{F}_{2}$ atmosphere for nine hours to produce $\mathrm{SF}_{6}$. The samples were purified cryogenically and by gas chromatography and introduced by $\mathrm{SF}_{6}$ line into a Thermo Electron MAT 253 mass spectrometer fitted with a dual inlet to measure ${ }^{32} \mathrm{SF}_{5}{ }^{+},{ }^{33} \mathrm{SF}_{5}{ }^{+},{ }^{34} \mathrm{SF}_{5}{ }^{+}$, and ${ }^{36} \mathrm{SF}_{5}{ }^{+}$. Sulfur isotopic ratios are expressed on the V-CDT scale, on which the $\delta^{34} \mathrm{~S}, \Delta^{33} \mathrm{~S}$, and $\Delta^{36} \mathrm{~S}$ values of the $\mathrm{Ag}_{2} \mathrm{~S}$ reference material, IAEA-S- 1 , are taken to be $-0.3 \%$, $0.094 \%$, and $-0.7 \%$, respectively (Wing and Farquhar, 2015). The precision and accuracy of the bulk fluorination system is evaluated by repeat analyses that return uncertainty (2SD) on $\delta^{34} \mathrm{~S}, \Delta^{33} \mathrm{~S}$, and $\Delta^{36} \mathrm{~S}$ values as better than $0.15 \%$, $0.02 \%$ and $0.4 \%$, respectively. The $\Delta^{33} S$ and $\Delta^{36} S$ values are calculated in the same manner as described in equation 2.

13

\subsection{Electron Backscatter Diffraction Analysis (EBSD)}

EBSD analysis of pentlandite to compare crystallographic orientation with multiple sulfur isotope analysis was undertaken on a Tescan MIRA3 field emission SEM at the Microscopy and Microanalysis Facility, John de Laeter Centre, Curtin University, Australia. Pentlandite from massive sulfide ore was analysed within four pucks that were prepared into a mount as described in the Supplementary Materials. Following standard petrographic diamond polishing, the mount was polished chemically and mechanically to $60 \mathrm{~nm}$ using colloidal silica in $\mathrm{pH} 10 \mathrm{NaOH}$. Prior to analysis the sample was coated with a $5 \mathrm{~nm}$ carbon film. EBSD data were acquired from a sample titled at $70^{\circ}$ using an Oxford Instruments Aztec 3.0 system operating at $12 \mathrm{kV}$, a beam intensity of $16 \mathrm{nA}$ and fixed working distance of $20 \mathrm{~mm}$. Pentlandite, pyrrhotite and magnetite orientation data were collected from each sample. Crystallographic data required to create the theoretical match units, by which empirically collected patterns are compared, were derived from Rajamani and Prewitt (1975) for pentlandite, Wechsler et al. (1984) for magnetite and Alsen (1925) for pyrrhotite. EBSD data were collected using the "mapping" mode of the Aztec EBSD software with a step size of 10 $\mu \mathrm{m}$, a minimum of 8 bands and a Hough resolution of 60 . In all cases, solutions gave mean angular deviation (MAD) values of $<1^{\circ}$ and calculation intergrain orientations are reproducible.

Post-processing of EBSD data was undertaken using Oxford Instruments Channel 5.12 software. Noise reduction protocols applied to the data were the Channel "wildspike" correction and a 5 nearest neighbour zero solution algorithm. EBSD data are shown as standard phase and inverse pole figure maps in the Supplementary Materials.

\section{MATERIALS}

Sulfides are inherently heterogeneous both chemically and mineralogically. Therefore, identifying natural specimens that may be used as sulfur isotope reference material is a difficult task whereby geological environment, pressure-temperature conditions, chemical composition, and grain size need to be considered. In the case of selecting reference material 
1 deposits demonstrate a more reasonable degree of chemical and isotopic homogeneity over small individual crystals that make up massive to sulfide-rich layers. For each of these sulfides, although the total volume amount of reference material characterized is small (in order to ascertain isotopic homogeneity), advancements in SIMS and LA-ICPMS capabilities and procedures (i.e., new sample holder geometry in SIMS; Peres et al. 2012; and large volume cells in LA-ICPMS) allow for the repeat use of the same reference material mounted in standard blocks.

In the case of pyrrhotite and pentlandite, these two sulfide phases are commonly exsolved from a monosulfide solid solution and typically have intra-grain associations in magmatic environments (Durazzo and Taylor, 1982; Kelly and Vaughn, 1983). Furthermore, the chemical compositions of pyrrhotite $\left(\mathrm{Fe}_{(1-\mathrm{x})} \mathrm{S} ; \mathrm{x}=0.0-0.2\right)$ and pentlandite $(\mathrm{Fe}, \mathrm{Ni})_{9} \mathrm{~S}_{8}$ are variable, reflective of conditions under which they formed. Pyrrhotite and pentlandite do not commonly form large hydrothermally-derived crystals, and so characterized reference material is derived from a small piece of a sulfide-rich and massive sulfide horizon, respectively. Images of the reference materials are presented in the Supplementary Materials. The effects of intra-grain and inter-grain textures on isotopic and chemical homogeneity of pyrrhotite and pentlandite reference materials are assessed in sections 4.3 and 4.4. Additional discussion on selecting reference materials is presented in section 5.1.

\section{1 $\quad$ Pyrite - Sierra}

Sierra is a $2 \mathrm{~cm}^{3}$ cube from a large $9 \mathrm{~kg}$ cube of pyrite sourced from a mine in the Cretaceous stratigraphy of the Sonora region of Mexico. Although the exact provenance is unknown, the area experienced widespread igneous activity during the late Cretaceous, resulting in the formation of widespread porphyry copper mineralisation across the region (Barra and Valencia, 2014). Sierra is mounted as $0.5 \mathrm{~mm}$ wide fragments of pyrite from the $2 \mathrm{~cm}^{3}$ cube of Sierra for SIMS analysis.

\subsection{Chalcopyrite - Nifty-b}

30 The Nifty-b is a $2 \mathrm{~cm}^{3}$ piece of a larger $8 \mathrm{~cm}^{3}$ grain of chalcopyrite from the Nifty copper deposit in the Proterozoic Paterson Orogen of Western Australia. Mineralization is hosted by the Nifty stratigraphic member of the Yeneena Supergroup and occurs as hydrothermal chalcopyrite-quartz-dolomite replacement of low grade shale (Anderson et al., 2001). Nifty-b is mounted as $0.5 \mathrm{~mm}$ wide fragments of chalcopyrite pyrite from the $2 \mathrm{~cm}^{3}$ piece of Nifty-b for SIMS analysis.

\subsection{Pyrrhotite - Alexo}

The Alexo monoclinic pyrrhotite forms subhedral $0.1-2 \mathrm{~mm}$ grains within a matrix of peridotite. It is from the nickel-sulfide Alexo deposit within the ca. 2.7 Ga Abitibi granitegreenstone belt of the Superior Craton, Canada. The sample comprises magmatic pyrrhotite grains composed of disseminated to net-textured sulfides at the contact between olivine cumulate komatiite rocks of the Munro Group and footwall andesitic rocks of the Hunter Mine Group (Naldrett, 1966). The local metamorphic grade at Alexo is prehnite-pumpellyite- 
1 Alexo is assumed to have occurred at ca. 2.7 Ga (Fyon and Green, 1991), which is coeval with other world-class komatiite-hosted nickel-sulfide systems worldwide (Barnes et al., 2013; Fiorentini et al., 2011; 2010). The Alexo sample was first isotopically defined by Bekker et al. (2009). A $2 \mathrm{~cm} \times 3 \mathrm{~cm} \times 0.5 \mathrm{~cm}$ pyrrhotite-rich layer of peridotite was trimmed from a larger hand sample. Alexo is mounted as $1 \mathrm{~mm}$ diameter pucks from this sample for

\subsection{Pentlandite - VMSO}

The VMSO pentlandite is from an amphibolite-facies massive sulfide lens from the Victor South shoot in the komatiite hosted nickel-sulfide Long-Victor deposit of the Kambalda camp. The Kambalda camp is situated in the ca. 2.7 Ga Kalgoorlie Terrane in the Yilgarn Craton of Western Australia (Barnes et al., 2013 and references therein). At Kambalda, nickel-sulfide deposits are associated with thick channelized komatiite flow units in stratigraphic contact with a thick pile of pillowed and massive tholeiitic basalts (Lunnon Basalt Formation), locally overlain by sulfidic metasedimentary rocks (e.g., Lesher and Groves, 1986). Subsequent folding has rotated the komatiitic channels from $30^{\circ}$ to a vertical dip to the east and $10^{\circ}$ plunge to the south as well as resulting in the localised remobilisation of some of the original sulfides into new structurally controlled positions (Stone et al., 2005). The VMSO sample was first isotopically defined by Bekker et al. (2009). It comprises 0.1$0.5 \mathrm{~mm}$ magmatic pentlandite grains interlayered at the $\mathrm{cm}$-scale with pyrrhotite and pyrite from the basal sulfide layer of the Silver Lake Member of the Kambalda Formation. A $1 \mathrm{~cm}$ wide pentlandite rich layer trimmed from the sample. From this layer, VMSO is mounted as 1 mm diameter pucks from the host massive sulfide lens for SIMS analysis.

\section{RESULTS}

The following section presents chemical and isotopic results pertaining to standard development work for four new sulfide reference materials: pyrite (Sierra), chalcopyrite (Nifty-b), pyrrhotite (Alexo), and pentlandite (VMSO). A summary of mineral chemical composition collected by WDS for each reference material is presented in Table 1. The main sulfide forming elements and common trace elements are presented in the Supplementary Materials. Figure 2 shows select elemental maps (by WDS) of reference material.

Table 1: Summary of the chemical composition determined by wavelength dispersive spectrometry. Uncertainty is two standard deviations (2SD).

\begin{tabular}{|c|c|c|c|c|c|c|}
\hline \multirow{2}{*}{ Standard } & \multirow{2}{*}{ Mineral } & \multirow{2}{*}{ Formula } & \multicolumn{4}{|c|}{ Chemical composition (wt.\%) } \\
\cline { 4 - 7 } & & & Fe (2SD) & Other (2SD) & Co (2SD) & S (2SD) \\
\hline \multirow{2}{*}{ Sierra } & Pyrite & $\mathrm{FeS}_{2}$ & $\begin{array}{c}53.3 \\
(0.5)\end{array}$ & - & - & $\begin{array}{c}46.7 \\
(0.4)\end{array}$ \\
\hline \multirow{2}{*}{ Nifty-b } & \multirow{2}{*}{ Chalcopyrite } & \multirow{2}{*}{$\mathrm{CuFeS}_{2}$} & $\begin{array}{c}34.5 \\
(1.4)\end{array}$ & $\begin{array}{c}\text { Cu: } 29.8 \\
(1.2)\end{array}$ & - & $\begin{array}{c}34.7 \\
(0.5)\end{array}$ \\
\hline
\end{tabular}




\begin{tabular}{|c|c|c|c|c|c|c|}
\hline \multirow{2}{*}{ Alexo } & Pyrrhotite & \multirow{2}{*}{$\mathrm{Fe}_{0.90} \mathrm{~S}$} & $\begin{array}{c}60.5 \\
(1.2)\end{array}$ & - & - & $\begin{array}{c}38.6 \\
(0.4)\end{array}$ \\
\hline \multirow{2}{*}{ VMSO } & \multirow{2}{*}{ Pentlandite } & $\mathrm{Fe}_{4.1} \mathrm{Ni}_{4.8} \mathrm{Co}_{0.1} \mathrm{~S}_{8}$ & $\begin{array}{c}29.4 \\
(0.8)\end{array}$ & $\begin{array}{c}\mathrm{Ni}: 35.8 \\
(0.9)\end{array}$ & $\begin{array}{c}0.3 \\
(0.1)\end{array}$ & $\begin{array}{c}32.9 \\
(0.4)\end{array}$ \\
\hline
\end{tabular}
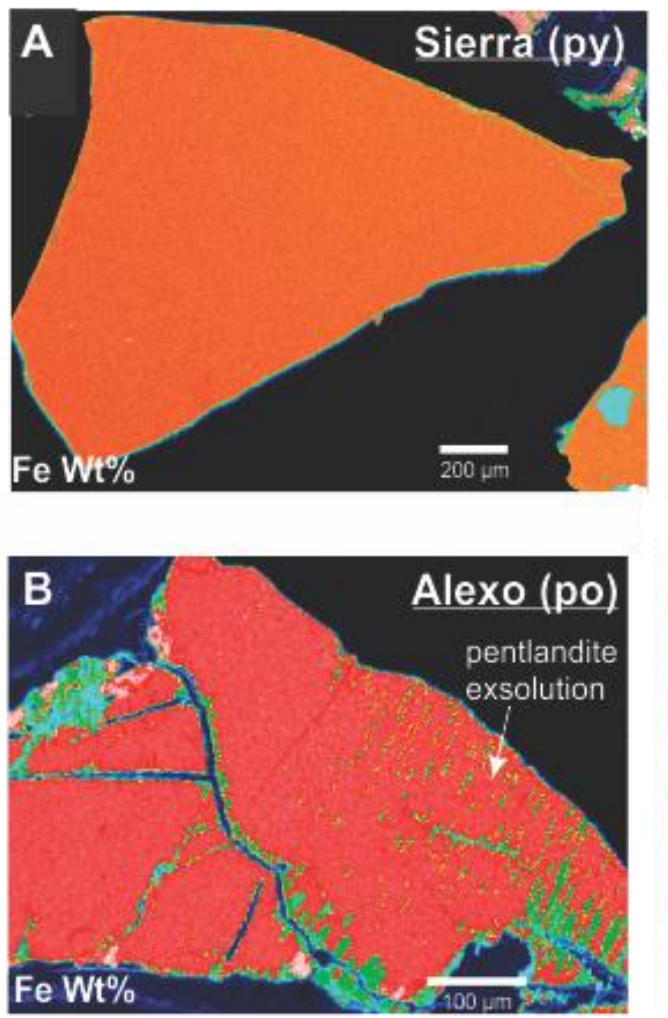
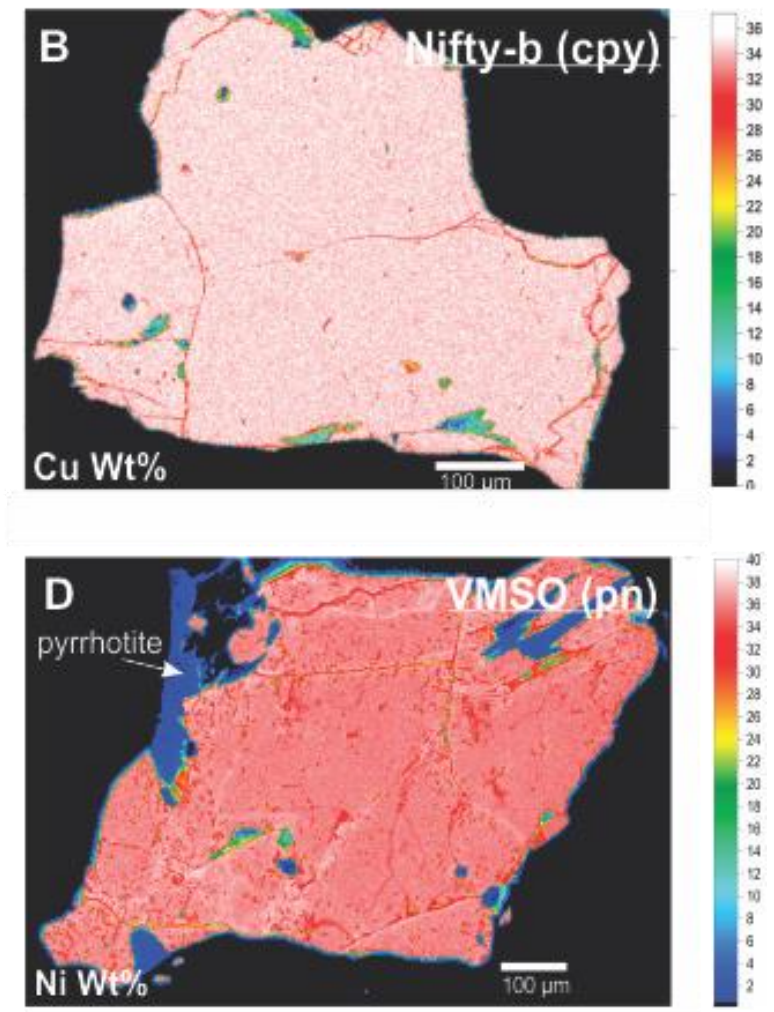

Figure 2: Compositional maps of: A) Sierra pyrite (Fe wt.\%), B) Nifty-b chalcopyrite (Cu wt.\%), C) Alexo pyrrhotite (Fe wt.\%), D) VMSO pentlandite (Ni wt.\%). Wavelength dispersive spectrometry maps are collected by EPMA.

Table 2 shows the accumulated SIMS isotopic data to define analytical repeatability of the four reference materials. Uncertainty reported in Table 2 and the text is twice the standard deviation of the mean. A compilation of in situ sulfur isotopic measurements for reference materials and unknown samples is presented in Supplementary Material.

Table 2: In situ SIMS sample repeatability for four presented reference materials and their corresponding uncertainty (reported as twice the standard deviation of the mean). " $n$ " is the number of measurements. 


\begin{tabular}{|c|c|c|c|c|c|}
\hline \multirow[t]{2}{*}{ Standard } & \multicolumn{5}{|c|}{ SIMS sample repeatability (\%o) } \\
\hline & $\begin{array}{c}\boldsymbol{\delta}^{\mathbf{3 3}} \mathbf{S} \\
(2 \mathrm{SD})\end{array}$ & $\begin{array}{c}\boldsymbol{\delta}^{\mathbf{3 4}} \mathbf{S} \\
(2 \mathrm{SD})\end{array}$ & $\begin{array}{c}\boldsymbol{\delta}^{\mathbf{3 6}} \mathbf{S} \\
(2 \mathrm{SD})\end{array}$ & $\begin{array}{c}\Delta^{\mathbf{3 3}} \mathbf{S} \\
(2 \mathrm{SD})\end{array}$ & $\begin{array}{l}\Delta^{\mathbf{3 6}} \mathbf{S} \\
(2 \mathrm{SD}) 1\end{array}$ \\
\hline $\begin{array}{l}\text { Sierra } \\
\text { (py) }\end{array}$ & $\begin{array}{c}0.15 \\
(n=1417)\end{array}$ & $\begin{array}{c}0.25 \\
(n=1417)\end{array}$ & $\begin{array}{c}0.90 \\
(n=861)\end{array}$ & $\begin{array}{c}0.08 \\
(n=1417)\end{array}$ & $\begin{array}{r}0.772 \\
(n=8613\end{array}$ \\
\hline $\begin{array}{l}\text { Nifty-b } \\
\text { (ccp) }\end{array}$ & $\begin{array}{c}0.14 \\
(n=149)\end{array}$ & $\begin{array}{c}0.23 \\
(n=149)\end{array}$ & $\begin{array}{c}0.63 \\
(n=87)\end{array}$ & $\begin{array}{c}0.08 \\
(n=150)\end{array}$ & $\begin{array}{r}0.484 \\
(n=88) 5\end{array}$ \\
\hline $\begin{array}{l}\text { Alexo } \\
\text { (po) }\end{array}$ & $\begin{array}{c}0.17 \\
(n=340)\end{array}$ & $\begin{array}{c}0.30 \\
(n=340)\end{array}$ & $\begin{array}{c}0.74 \\
(n=199)\end{array}$ & $\begin{array}{c}0.11 \\
(n=340)\end{array}$ & $\begin{array}{r}0.526 \\
(n=199)\end{array}$ \\
\hline $\begin{array}{l}\text { VMSO } \\
\text { (pn) }\end{array}$ & $\begin{array}{c}0.21 \\
(n=246)\end{array}$ & $\begin{array}{c}0.33 \\
(n=246)\end{array}$ & $\begin{array}{c}0.90 \\
(n=105)\end{array}$ & $\begin{array}{c}0.12 \\
(n=246)\end{array}$ & $\begin{array}{r}0.728 \\
(n=105 \delta\end{array}$ \\
\hline
\end{tabular}

10

11 Table 3 and text presents the weighted mean bulk sulfur isotope compositions $\left(\delta^{33} \mathrm{~S}_{\mathrm{V}-\mathrm{CDT}}\right.$,

$12 \delta^{34} \mathrm{~S}_{\mathrm{V}-\mathrm{CDT}}, \delta^{36} \mathrm{~S}_{\mathrm{V}-\mathrm{CDT}}$ ) measured by fluorination gas-source mass spectrometry (from multiple

13 aliquots of each reference material) and associated uncertainty, defined as two standard

14 deviations of the mean. All sulfur isotope results presented in the text are reported on the V-

15 CDT scale. Figure 3 demonstrates $\delta^{34} \mathrm{~S}$ isotope homogeneity of the reference materials. To

16 demonstrate that the reference material was homogeneous within the analytical uncertainty of

17 the fluorination gas-source mass spectrometry, an MSWD test was completed as detailed in

18 Wing and Farquhar (2015). Briefly, a population was considered homogeneous if all values

19 within a given sample population were consistent with a single mean value and returned

20 within a 95\% confidence interval. Because the analytical error is well defined, MSWD is

21 used to estimate an independent "goodness of fit" to demonstrate separately that the reference

22 material is homogeneous and consistent within a single mean value. Bulk fluorination data

23 for four new reference materials are presented in the Supplementary Material.

24

25 Table 3: Weighted mean bulk sulfur isotope compositions $\left(\delta^{33} \mathrm{~S}_{\mathrm{V}-\mathrm{CDT}}, \delta^{34} \mathrm{~S}_{\mathrm{V}-\mathrm{CDT}}, \delta^{36} \mathrm{~S}_{\mathrm{V}-\mathrm{CDT}}\right.$,

$26 \Delta^{33} \mathrm{~S}_{\mathrm{V}-\mathrm{CDT}}, \Delta^{36} \mathrm{~S}_{\mathrm{V}-\mathrm{CDT}}$ ) as measured by fluorination gas-source mass spectrometry. $2 \mathrm{SD}$ is two

27 standard deviations of the mean. SE is the standard error associated with the mean, and

28 MSWD is an independent goodness-of-fit check after Wing and Farquhar (2015). " $n$ " is the

29 number of independent extractions and measurements of separate aliquots.

\begin{tabular}{|c|c|c|c|c|c|c|c|c|c|c|c|c|c|c|c|}
\hline \multirow[t]{2}{*}{ Ref. } & & \multicolumn{14}{|c|}{ Bulk measurement (\%o) } \\
\hline & $n$ & $\delta^{33} S$ & 2SD & $1 \mathrm{SE}$ & MSWD & $\delta^{34} \mathbf{S}$ & 2SD & $1 \mathrm{SE}$ & MSWD & $\delta^{36} \mathbf{S}$ & 2SD & $1 \mathrm{SE}$ & MSWD & $\begin{array}{c}\boldsymbol{\Delta}^{\mathbf{3 3}} \mathbf{S} \\
(2 \mathrm{SD})\end{array}$ & $\begin{array}{c}\boldsymbol{\Delta}^{\mathbf{3 6}} \mathbf{S} \\
(2 \mathrm{SD})\end{array}$ \\
\hline $\begin{array}{c}\text { Sierra } \\
\text { (py) }\end{array}$ & 12 & 1.09 & 0.15 & 0.02 & 0.99 & 2.17 & 0.28 & 0.04 & 0.89 & 3.96 & 0.60 & 0.09 & 1.00 & $\begin{array}{l}-0.02 \\
(0.01)\end{array}$ & $\begin{array}{l}-0.18 \\
(0.15)\end{array}$ \\
\hline $\begin{array}{c}\text { Nifty-b } \\
\text { (ccp) }\end{array}$ & 5 & -1.78 & 0.21 & 0.03 & 2.08 & -3.58 & 0.44 & 0.07 & 2.22 & -7.15 & 0.63 & 0.13 & 1.11 & $\begin{array}{l}-0.06 \\
(0.03)\end{array}$ & $\begin{array}{l}-0.36 \\
(0.45)\end{array}$ \\
\hline $\begin{array}{c}\text { Alexo } \\
\text { (po) }\end{array}$ & 9 & 1.73 & 0.20 & 0.03 & 1.87 & 5.23 & 0.40 & 0.05 & 1.77 & 10.98 & 0.59 & 0.10 & 0.95 & $\begin{array}{l}-0.96 \\
(0.04)\end{array}$ & $\begin{array}{c}1.02 \\
(0.27)\end{array}$ \\
\hline $\begin{array}{c}\text { VMSO } \\
\text { (pn) }\end{array}$ & 11 & 1.66 & 0.24 & 0.02 & 2.67 & 3.22 & 0.51 & 0.05 & 2.89 & 6.37 & 0.83 & 0.09 & 1.92 & $\begin{array}{c}0.00 \\
(0.02)\end{array}$ & $\begin{array}{c}0.24 \\
(0.35)\end{array}$ \\
\hline
\end{tabular}

\section{0}




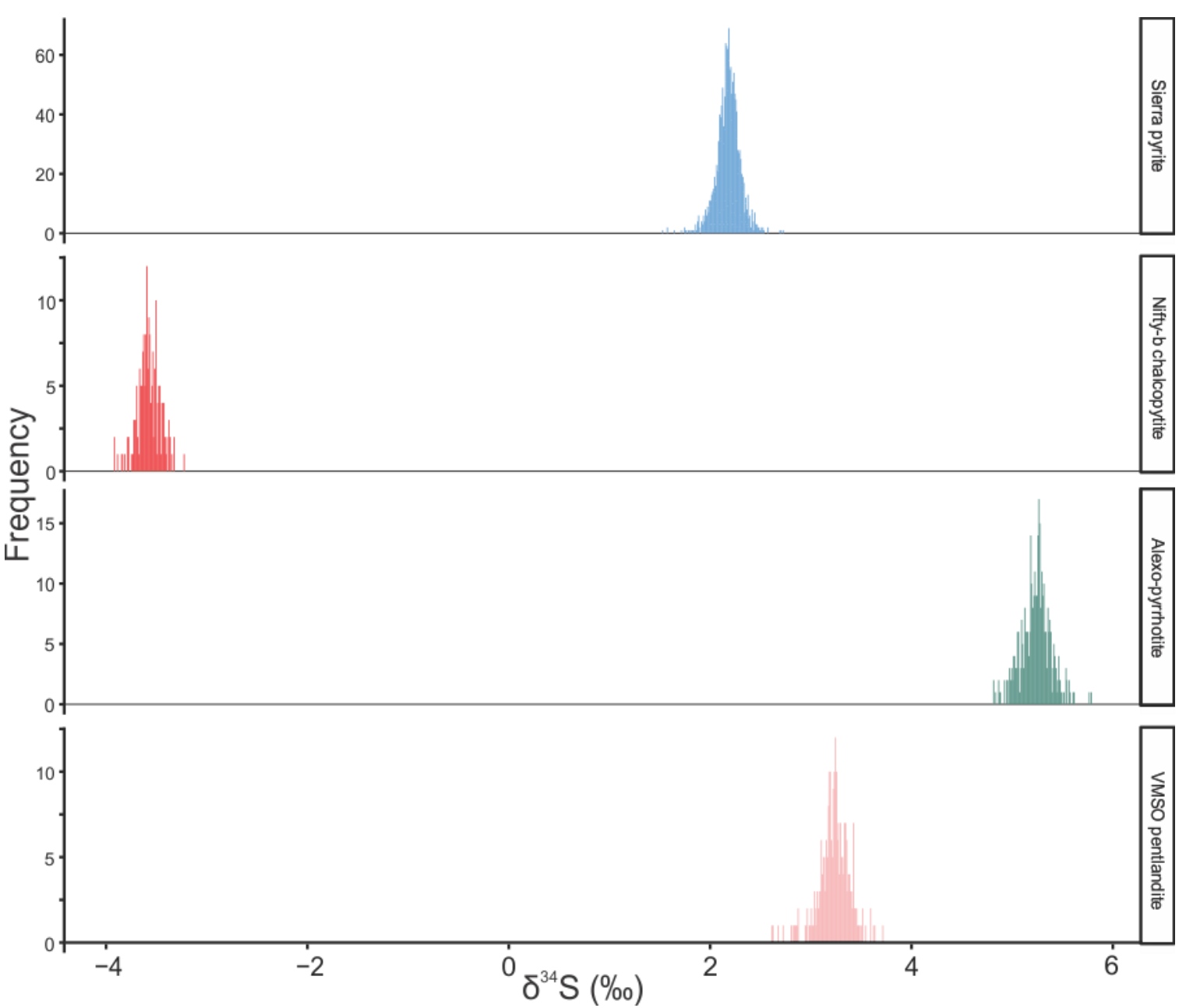

2 Figure 3: Probability density plots for $\delta^{34} \mathrm{~S}$ for normalized reference material to demonstrate the low degree of 3 uncertainty, normal distribution and lack of outliers.

\subsection{Pyrite - Sierra}

6 The chemical composition of Sierra, determined by EPMA ( $n=78$ from five fragments),

7 reveals that it is composed of $46.7 \pm 0.5 \mathrm{wt} . \% \mathrm{Fe}$ and $53.3 \pm 0.4 \mathrm{wt} . \% \mathrm{~S}$, with trace amount of

8 Co ( 400 ppm). WDS mapping further demonstrates that Sierra grain fragments are

9 chemically homogeneous (Figure 2a) and free of inclusions. Twelve different fragments of

10 the $2 \mathrm{~cm}^{3}$ piece known as Sierra were analysed by fluorination gas-source mass spectrometry

11 and yielded weighted averaged values of: $\delta^{33} \mathrm{~S}=1.09 \pm 0.15 \%$, $\delta^{34} \mathrm{~S}=2.17 \pm 0.28 \%$, and

$12 \delta^{36} \mathrm{~S}=3.96 \pm 0.60 \%$. Values for $\Delta^{33} \mathrm{~S}$ and $\Delta^{36} \mathrm{~S}$ are calculated as $-0.02 \pm 0.01 \%$ and $0.18 \pm$

$130.15 \%$, respectively, indicating that Sierra does not contain a MIF signature. Sierra has been

14 measured as a primary reference for triple sulfur isotopes 1417 times amongst which 861

15 times included quadruple sulfur isotopes over 59 analytical sessions (see Figure 3).

16 Reproducibility of SIMS analyses on Sierra was $\delta^{33} \mathrm{~S}=0.15 \%, \delta^{34} \mathrm{~S}=0.24 \%$, and $\delta^{36} \mathrm{~S}=$

17 1.04\%. Reproducibility on $\Delta^{33} \mathrm{~S}=0.08 \%$ and $\Delta^{36} \mathrm{~S}=0.77 \%$. Different fragments of the

18 much larger pyrite, known as 'Sonora', have been described by Farquhar et al. (2013), Evans

19 et al. (2014) and Wacey et al. (2011). The Sonora fragments have slightly lighter values of

$20 \delta^{33} \mathrm{~S}(0.83 \%), \delta^{34} \mathrm{~S}(1.61 \%)$, and $\delta^{36} \mathrm{~S}(3.25 \%)$ than those we determine here for Sierra.

$22 \quad 4.2 \quad$ Chalcopyrite - Nifty-b 
1 WDS analyses $(n=352)$ reveal that Nifty-b chalcopyrite is composed of $34.5 \pm 1.4 \mathrm{wt} . \% \mathrm{Cu}$, $229.8 \pm 1.2 \mathrm{wt} . \% \mathrm{Fe}$, and $34.7 \pm 0.5 \mathrm{wt} . \% \mathrm{~S}$, with trace amounts of $\mathrm{Zn}(\sim 300 \mathrm{ppm})$. WDS

3 mapping demonstrates that Nifty-b is homogeneous and inclusion-free but contains fractures

4 that can be avoided during isotope measurements (Figure 2b). Five different grain fragments

5 of Nifty-b were analysed by fluorination gas-source mass spectrometry and yielded a

6 weighted average of: $\delta^{33} \mathrm{~S}=-1.78 \pm 0.21 \%$, $\delta^{34} \mathrm{~S}=-3.58 \pm 0.44 \%$, and $\delta^{36} \mathrm{~S}=-7.15 \pm 0.63 \%$.

7 Values for $\Delta^{33} \mathrm{~S}$ and $\Delta^{36} \mathrm{~S}$ are calculated as $0.06 \pm 0.03 \%$ and $0.36 \pm 0.50 \%$, respectively (the

8 large error on $\Delta^{36} \mathrm{~S}$ prevents observation of MIF in this isotopic system). Nifty-b has a small

9 but consistent MIF signature. Nifty-b has been measured as a primary chalcopyrite reference

10 for triple sulfur isotopes 149 times, and for quadruple sulfur isotopes 87 times in 15

11 analytical sessions over the course of three years. Average measurement repeatability of

12 SIMS analyses on Nifty-b was $\delta^{33} \mathrm{~S}=0.14 \%$, $\delta^{34} \mathrm{~S}=0.23 \%$, and $\delta^{36} \mathrm{~S}=0.63 \%$.

13 Reproducibility on $\Delta^{33} \mathrm{~S}=0.08 \%$ and $\Delta^{36} \mathrm{~S}=0.48 \%$.

14

\section{$4.3 \quad$ Pyrrhotite - Alexo}

Alexo pyrrhotite has very fine exsolution lamellae, $<10 \mu \mathrm{m}$ in width, which are heterogeneously dispersed. WDS analyses of Alexo $(n=61)$ reveal that it is composed of $60.5 \pm 1.2$ wt. $\% \mathrm{Fe}$ and $38.6 \pm 0.4$ wt. $\% \mathrm{~S}$. Exsolution lamellae are composed of cobaltbearing pentlandite with a composition of $32.3 \pm 1.7 \mathrm{wt} . \% \mathrm{Fe}, 32.3 \pm 1.5 \mathrm{wt} . \% \mathrm{Ni}, 1.2 \pm 0.1$ wt. $\% \mathrm{Co}$, and $33.1 \pm 0.6$ wt. $\% \mathrm{~S}(n=23)$. These pentlandite lamellae are very fine and WDS mapping demonstrates that they are unevenly distributed throughout the grain (see Figure 2c), making them difficult to observe during SIMS analysis. Alexo pyrrhotite contains inclusions of magnetite $(50 \mu \mathrm{m})$ and conjugate fracture sets; both features can be readily avoided during SIMS analysis.

Nine different grains of Alexo were analysed by fluorination gas-source mass spectrometry and yielded a weighted average of: $\delta^{33} \mathrm{~S}=1.73 \pm 0.20 \%$, $\delta^{34} \mathrm{~S}=5.23 \pm 0.40 \%$, and $\delta^{36} \mathrm{~S}=$ $10.98 \pm 0.59 \%$. Uncertainty is reported as the standard error of the mean. Values for $\Delta^{33} \mathrm{~S}$ and $\Delta^{36} \mathrm{~S}$ are calculated as $-0.96 \pm 0.04 \%$ and $1.02 \pm 0.27 \%$, respectively, indicating that Alexo has a MIF signature. The values represent the bulk composition of Alexo, incorporating both pyrrhotite and the pentlandite exsolution lamellae. Alexo has been measured as a primary pyrrhotite reference for triple sulfur isotopes 340 times, and for quadruple sulfur isotopes 199 times in 27 analytical sessions (see Figure 5). Reproducibility of SIMS analyses on Alexo was $\delta^{33} \mathrm{~S}=0.17 \%$, $\delta^{34} \mathrm{~S}=0.30 \%$, and $\delta^{36} \mathrm{~S}=0.74 \%$. Reproducibility on $\Delta^{33} \mathrm{~S}=0.11 \%$ and $\Delta^{36} \mathrm{~S}=0.52 \%$.

\subsubsection{The effect of pentlandite exsolution in Alexo pyrrhotite}

Unmixing of the solid solution pyrrhotite-pentlandite (Fe,Ni) ${ }_{1-x} \mathrm{~S}$ at temperatures below $\sim 600$ ${ }^{\circ} \mathrm{C}$ via exsolution of pentlandite is a common and ubiquitous petrochemical feature of magmatic nickel-sulfide ore deposits (e.g., Kelly and Vaughn, 1983; Naldrett et al., 1967). To unravel and decipher the sulfur isotopic record hosted by pyrrhotite grains from magmatic deposits, it is important to understand the effect of potential isotope fractionation between the two phases of the Alexo pyrrhotite reference material (also derived from a magmatic ore deposit). The sulfur isotopic composition of Alexo, determined by fluorination gas-source 
mass spectrometry, itself incorporates a small amount (1-5\%) of pentlandite exsolution. This investigation is crucial because: 1) lamellae may be fast pathways of isotopic exchange in an

3 open system, 2) instrumental mass fractionation may be affected by the incorporation of more 4 than one phase (see Hervig et al., 2002), and 3) natural isotopic fractionation of pentlandite5 pyrrhotite may be reflected in the bulk analysis and not represented in the SIMS analysis 6 (when avoiding exsolution lamellae).

Because lamellae are so fine and difficult to observe even with adequate BSE imaging, it is impossible to solely analyse exsolution lamellae (Figure 4). Therefore, to evaluate the effect on sulfur isotope composition of the presence of exsolution lamellae within Alexo pyrrhotite on sulfur isotope composition, 60 in situ analyses were carried out in two groupings: 1) 30 analyses of areas with an abundance of exsolution lamellae, and 2) 30 analyses of areas free from exsolution lamellae. Alexo grains were reimaged after SIMS work to identify which analyses incorporated some component of exsolution lamellae (Figure 9). Group one yields average $\delta^{33} \mathrm{~S}, \delta^{34} \mathrm{~S}, \delta^{36} \mathrm{~S}$ values equal to $1.75 \pm 0.20 \%$, $5.27 \pm 0.43 \%$, and $11.12 \pm 0.98 \%$, respectively. Group two yields average $\delta^{33} \mathrm{~S}, \delta^{34} \mathrm{~S}, \delta^{36} \mathrm{~S}$ values equal to $1.70 \pm 0.22 \%$, $5.18 \pm$ $0.44 \%$, and $10.83 \pm 0.98 \%$, respectively. Analyses for the entire run were normalised to the bulk value of Alexo, a value that incorporates some component of pentlandite exsolution, but that returns a low MSWD (1.8) across nine separate grain extractions and analyses. These results demonstrate that exsolution of pentlandite within Alexo pyrrhotite are minimal enough to be masked by the measurement repeatability and so do not impact sulfur isotope measurements. Therefore, Alexo is an adequate reference material for the determination of sulfur isotope composition of pyrrhotite.




1 Figure 4: Example of compositionally homogeneous area of Alexo pyrrhotite compared to areas of significant pentlandite exsolution. Raster spots show examples of assessment of two different areas of the grain to determine effect on instrumental mass fractionation.

\subsection{Pentlandite - VMSO}

6 WDS analyses demonstrate that VMSO pentlandite is composed of $29.4 \pm 0.8 \mathrm{wt} . \% \mathrm{Fe}, 35.8$ \pm 0.9 wt. $\% \mathrm{Ni}, 0.3 \pm 0.1 \mathrm{wt} . \% \mathrm{Co}$, and $32.9 \pm 0.4 \mathrm{wt} . \% \mathrm{~S}(n=45)$, with trace amounts of $\mathrm{Sb}$ $(\sim 150 \mathrm{ppm}), \mathrm{Se}(\sim 600 \mathrm{ppm})$ and $\mathrm{Cu}(\sim 500 \mathrm{ppm})$. VMSO pentlandite contains small ( 100 $\mu \mathrm{m})$ inclusions of magnetite and is intergrown with pyrrhotite and pyrite. WDS mapping demonstrates that the pentlandite portion of VMSO is homogeneous but that fractures and sulfide intergrowths should be avoided (Figure 4d). Analysis of the intergrowths reveal compositions of $59.5 \pm 0.6 \mathrm{wt} . \% \mathrm{Fe}$ and $39.3 \pm 0.1 \mathrm{wt} . \% \mathrm{~S}$, for pyrrhotite $(n=13)$ and $45.6 \pm$ 0.2 wt. $\% \mathrm{Fe}, 0.9 \pm 0.0 \mathrm{wt} . \% \mathrm{Co}$, and $53.5 \pm 0.2 \mathrm{wt} . \% \mathrm{~S}$, for pyrite $(n=11)$. The pyrrhotite and pyrite components and oxide inclusions are readily identified in BSE imaging and can be easily avoided during SIMS analysis.

Eleven different grains of the pentlandite portion of VMSO were analysed by fluorination gas-source mass spectrometry and yielded a weighted average of: $\delta^{33} \mathrm{~S}=1.66 \pm 0.24 \%$, $\delta^{34} \mathrm{~S}$ $=3.22 \pm 0.51 \%$, and $\delta^{36} \mathrm{~S}=6.37 \pm 0.83 \%$. Uncertainty is reported as the standard error of the mean. Values for $\Delta^{33} \mathrm{~S}$ and $\Delta^{36} \mathrm{~S}$ are calculated as $0.00 \pm 0.02 \%$ and $0.24 \pm 0.35 \%$, respectively, indicating that VMSO does not have a MIF signature. The elevated MSWD on sulfur isotope measurements of VMSO is discussed in section 5.1.3. VMSO has been measured as a primary pentlandite reference for triple sulfur isotopes 255 times, and for quadruple sulfur isotopes 98 times in 22 analytical sessions (see Figure 5). Reproducibility of SIMS analysis on VMSO was $\delta^{33} \mathrm{~S}=0.21 \%$, $\delta^{34} \mathrm{~S}=0.33 \%$, and $\delta^{36} \mathrm{~S}=0.90 \%$. Reproducibility on $\Delta^{33} \mathrm{~S}=0.12 \%$ and $\Delta^{36} \mathrm{~S}=0.72 \%$.

\subsubsection{Investigation into the homogeneity of VMSO pentlandite}

Bulk measurements of VMSO pentlandite yield larger uncertainties and greater MSWD values $\left(\delta^{33} \mathrm{~S}=1.66 \pm 0.23 \%\right.$ (MSWD 2.67), $\delta^{34} \mathrm{~S}=3.22 \pm 0.51 \%$ (MSWD 2.89), and $\delta^{36} \mathrm{~S}=$ $6.37 \pm 0.83 \%$ o (MSWD 1.92)) than other sulfide reference material, indicating that it is a more isotopically heterogeneous material. Pentlandite does not exist naturally as large single crystals; therefore, this reference material has a certain level of isotopic heterogeneity attributed to micro-scale intergrowths of pentlandite and pyrrhotite within the reference material, a feature typical of sulfide ore in magmatic deposits. Although these two sulfide phases are cogenetic, slightly different isotopic compositions between the two phases are expected due to natural equilibrium isotopic fractionation. The $<\mathrm{mm}$-scale intergrowths are large enough to be easily avoidable during SIMS analysis; however, the incorporation of a small component of pyrrhotite during extraction of (relatively) large volumes of sulfur for bulk analysis is unavoidable (see pyrrhotite-pentlandite intergrowth in Figure $2 \mathrm{~d}$ ). SIMS analyses of the pyrrhotite intergrowths were normalized using Alexo pyrrhotite. Sulfur isotope analysis of pyrrhotite intergrowths yielded values of $\delta^{33} \mathrm{~S}=2.07 \pm 0.26 \%$, $\delta^{34} \mathrm{~S}=$ 
$1 \quad 3.86 \pm 0.18 \%$, and $\delta^{36} \mathrm{~S}=8.09 \pm 0.26 \%$. These values are slightly elevated to the determined 2 isotopic composition of VMSO pentlandite but within the envelope of uncertainty. Therefore,

3 the uncertainty on the bulk values mask the incorporation of a component of pyrrhotite

4 during the extraction process. We determine VMSO reference material to be adequate for in

5 situ sulfur isotope analysis of pentlandite but to be used with the expectation of propagating

6 poorer analytical precision.

\section{DISCUSSION}

9 Mineral systems are natural laboratories that provide invaluable information on the flux of

10 metals and fluids that are cycled among the different reservoirs of our planet. Most of this

11 information is stored as chemical and isotopic signatures, which are preserved in the

12 magmatic and hydrothermal sulfide phases that comprise the mineralization hosted in

13 different mineral systems. However, the interpretation of the information stored in sulfides requires care, as the minero-chemical features of sulfides are prone to be reset over a wide range of physical conditions. The resulting complexity recorded in the chemical and isotopic nature of any given sulfide assemblage may be cryptic to bulk rock analysis, but can be resolved with an in situ analytical approach, which allows the investigator to carefully select specific grains or crystal fractions and avoid others.

\subsection{Selecting and validating sulfide reference material}

In the case of selecting reference material for pyrite and chalcopyrite, small pieces $\left(\sim 2 \mathrm{~cm}^{3}\right)$ of much larger crystals from low grade hydrothermal deposits yield a much higher degree of chemical and isotopic homogeneity over small individual crystals that make up sulfide-rich layers. Here, we demonstrate this fact by comparing the Sierra standard (a fragment of a large hydrothermal crystal) to other available pyrite sulfur isotope standards that occur as small individual grains within a stratigraphic horizon.

Grains of Isua 248474 pyrite (kindly supplied by Martin Whitehouse) from the Isua greenstone belt, SW Greenland (Whitehouse, 2013) were used as secondary standards to assess the adequacy of Sierra as a reference material. Isua 248474 has reported bulk sulfur isotope values of $\delta^{33} \mathrm{~S}=4.33 \pm 0.24 \%$ o $(1 \sigma), \delta^{34} \mathrm{~S}=1.99 \pm 0.18 \%$ ( $\left.1 \sigma\right)$ (Baublys et al., 2004). A total of 216 SIMS analyses (in 19 analytical sessions) have been completed on Isua 248474 pyrite as an unknown using Sierra as the primary reference material and yield an average of $\delta^{33} \mathrm{~S}=4.45 \pm 0.66 \%$, $\delta^{34} \mathrm{~S}=2.60 \pm 0.86 \%$, and $\delta^{36} \mathrm{~S}=2.74 \pm 1.60 \%$ and a calculated MIF signature: $\Delta^{33} \mathrm{~S}=3.11 \pm 0.33 \%$ and $\Delta^{36} \mathrm{~S}=-2.38 \pm 0.81 \%$. Variability within the Isua 248474 pyrite standard has been observed by Whitehouse (2013) who reports some dispersion to lower values for $\delta^{34} \mathrm{~S}$ but yields an average $\delta^{34} \mathrm{~S}$ that is higher but within error of the accepted bulk measurement of Baublys et al. (2004). Here, our Isua 248474 measurements normalised to Sierra have a high uncertainty, consistent with the isotopic variability observed by Whitehouse (2013).

42 A grain of UW Balmat pyrite (kindly supplied by John Craven) from the Adirondack 43 Mountains, New York was also assessed. UW Balmat pyrite was originally described by 44 Crowe et al. (1990) who reported $\delta^{34} \mathrm{~S}$ equal to $14.63 \pm 0.38 \%$ (2SD). Further to that, 
1 Graham and Valley (1992) describe the UW Balmat pyrite as only being isotopically

2 homogeneous at the $\sim 1.0 \%$ level. Pyrite from a slightly different stratigraphic section of the

3 deposit (UWPy-1) does not show any MIF anomaly (Williford et al., 2011). Two analytical

4 sessions for triple isotopes give 31 analyses of UW Balmat pyrite with an average $\delta^{34} \mathrm{~S}$ of

$516.23 \pm 0.18 \%$ (2SD). Our values for $\delta^{33} \mathrm{~S}$ equal $8.30 \pm 0.12 \%$ and yield a $\Delta^{33} \mathrm{~S}$ of $-0.03 \%$,

6 confirming the lack of a MIF signature. We attribute the variability in both the Isua 248474

7 and UW Balmat pyrite standards to being separate grains distributed between laboratories.

9 In the development of a chalcopyrite standard, four separate materials were tested for isotopic

10 homogeneity. Two materials were fragments of large hydrothermal chalcopyrite crystals

11 which yielded a much higher degree of $\delta^{34} \mathrm{~S}$ reproducibility than the two other materials

12 derived from massive sulfide horizons in magmatic systems. The pyrite and chalcopyrite

13 results demonstrate that small fragments of large hydrothermal sulfide crystals are more

14 isotopically homogeneous and more suitable standards than individual sulfide grains in

15 sulfide-rich layers.

16

17 In the case of pyrrhotite and pentlandite, these minerals do not commonly occur as large

18 hydrothermal crystals and so the most homogeneous reference material were selected from

19 massive sulfide layers from magmatic ore deposits. Preliminary investigation into how

20 chemical heterogeneity (i.e., micro-exsolution and intergrowths between the two phases)

21 affects isotopic homogeneity in sections 4.3 and 4.4, demonstrate that Alexo and VMSO

22 reference materials are suitable for the determination of sulfur isotope composition of

23 pyrrhotite and pentlandite and ideal for the investigation of magmatic deposits (in which

24 unknown sulfides will have similar textures). However, for comparison, further effort to

25 development a hydrothermal pyrrhotite standard is warranted.

26

We have presented chemical and isotopic compositions for a suite of chemically and isotopically homogeneous sulfide reference materials that are representative of the sulfide mineralogy of magmatic and hydrothermal mineral systems. Figure 5 presents plots of: 1) $\delta^{33} \mathrm{SV}_{\text {V-CDT Vs. }} \delta^{34} \mathrm{~S}_{\text {V-CDT }}$, and 2) $\Delta^{33} \mathrm{~S}$ vs. $\delta^{34} \mathrm{SV}_{\text {V-CDT }}$ for all reference material analysed in this study. Two of the four sulfide standards (pyrrhotite and chalcopyrite) contain a MIF component, a feature that is recommended to confidently assess the accuracy of $\Delta^{33} \mathrm{~S}$ and $\Delta^{36}$ S measurements (Whitehouse, 2013). SIMS measurements on the sulfur isotope dataset demonstrate that the reference materials are adequately isotopically homogeneous and return repeatability on the order of uncertainty on the bulk measurements. Furthermore, bulk measurements deem the reference material homogeneous by the MSWD test as detailed in 37 Wing and Farquhar (2015). 

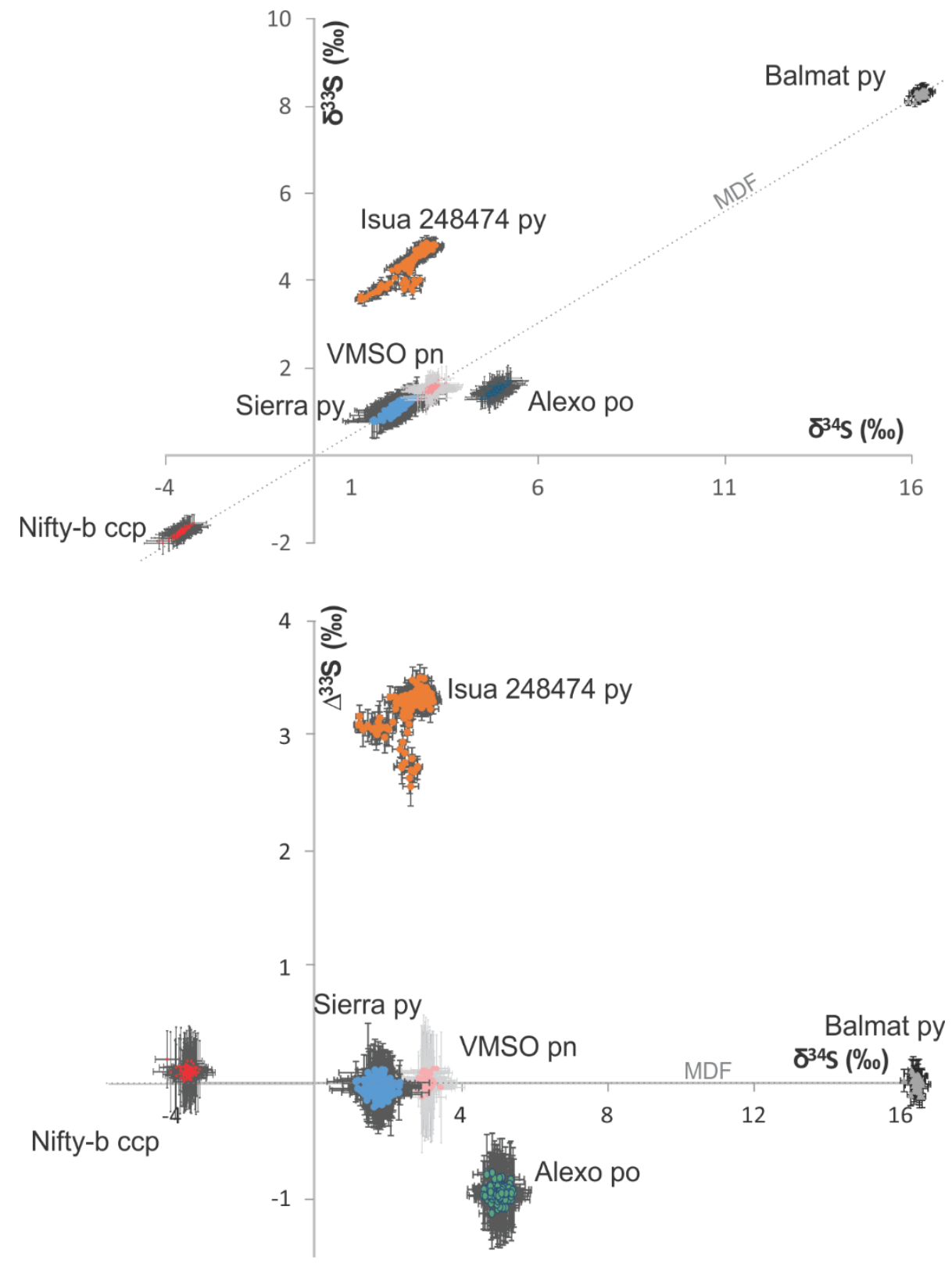

2 Figure 5: Plots of: (a) $\delta^{33} \mathrm{~S}_{\mathrm{V}-\mathrm{CDT}}$ Vs. $\delta^{34} \mathrm{~S}_{\mathrm{V}-\mathrm{CDT}}$ and (b) $\Delta^{33} \mathrm{SV}_{\mathrm{V}-\mathrm{CDT}} \mathrm{Vs} . \delta^{34} \mathrm{~S}_{\mathrm{V}-\mathrm{CDT}}$ for all sulfide reference material

3 (Sierra pyrite, Nifty-b chalcopyrite, Alexo pyrrhotite, and VMSO pentlandite) measured by SIMS in this study.

4 Error crosses are the overall uncertainty (at the 2SD level) based on propagating the individual analysis

5 repeatability with the reproducibility for the relevant analytical session. The Sierra pyrite is used as the primary

6 reference for measuring previously characterised pyrite reference material Isua 248474 and UW Balmat pyrite

7 (see Whitehouse, 2013; Graham and Valley, 1992).

$9 \quad 5.2 \quad$ In situ multiple sulfur isotope analysis of a nickel-sulfide deposit, Kambalda

10 The in situ SIMS multiple sulfur isotope data from this study are used to constrain the nature 11 of the ore-forming process in the Moran shoot, within the Kambalda camp of Western

12 Australia. The results are compared with existing data from the Victor South shoot along the 13 Victor channel, where the VMSO reference material was collected and analysed, in order to 14 reflect on the sulfur isotope architecture of the various channels exposed in the Long-Victor 15 deposit. The integrated dataset also permits discussion of the large-scale setting of the 16 Kambalda camp in relation to other world-class nickel-sulfide deposits in the Kalgoorlie 
1 Terrane of the Yilgarn Craton, which hosts the largest resources and reserves of nickel-

2 sulfide mineralisation associated with komatiites (Barnes and Fiorentini, 2012). We utilise

3 the case study to validate the presented reference material, assess the natural fractionation

4 factor of $\delta^{34} \mathrm{~S}$ between pyrrhotite and pentlandite, and assess whether crystallographic

5 orientation of pentlandite induces biases on $\delta^{34} \mathrm{~S}$ and $\Delta^{33} \mathrm{~S}$ measurements.

6

\subsubsection{Moran shoot, Long-Victor deposit, Kambalda camp}

8 The case study focussed on the identification of the multiple sulfur isotope signature of the major magmatic sulfide phases (pyrrhotite, pentlandite and chalcopyrite) hosted in the massive sulfide layer at the base of the Moran shoot at Kambalda, Western Australia. The spatial and genetic relationship between the Victor South shoot, where VMSO reference material was collected, and the Moran shoot, where the sample for the case study was collected, is discussed in Barnes et al. (2013) and presented in Figure 6. Briefly, the Moran shoot is hosted in the same channelized structure that hosts the larger Long shoot. This channel runs roughly parallel to the Victor channel in which the Victor South shoot is hosted. The Moran shoot attains $500 \mathrm{~m}$ along strike but is open to the south, where the boundaries of the mineralised body are not defined.

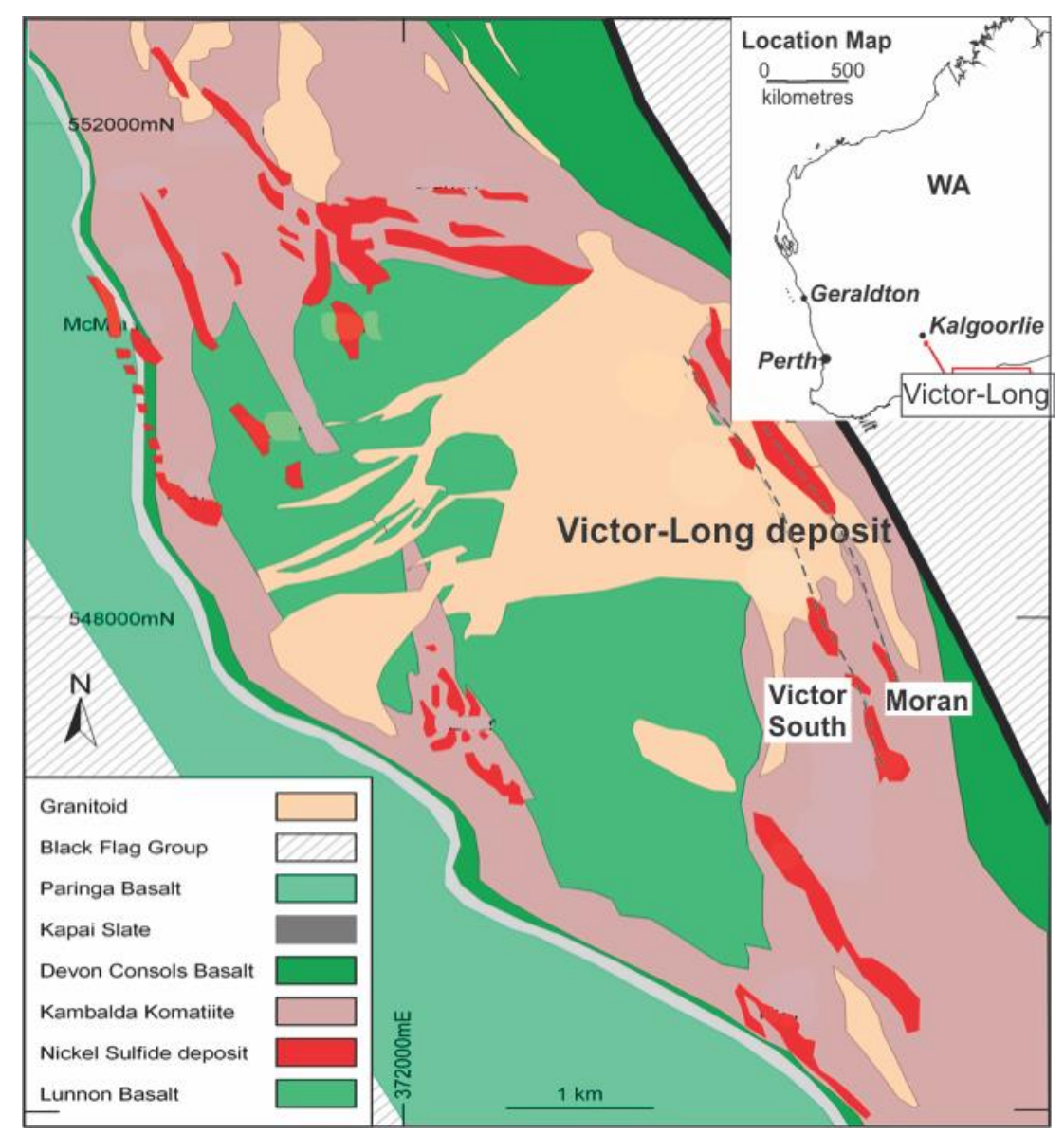

20 Figure 6: Location of the Victor-Long nickel-sulfide deposit of the Kambalda camp, Western Australia after Bekker et al. (2009) and references therein. The Victor-Long deposit is host to the Victor South and Moran shoots, discussed in this study. 
1 The ore body largely comprises massive and matrix sulfides dominantly composed of pentlandite (38\%) and pyrrhotite (58\%), with minor (4\%) chalcopyrite (Figure 7). Pyrrhotite and pentlandite are intergrown and are in equilibrium. Chalcopyrite forms small $(<40 \mu \mathrm{m})$ interstitial grains in equilibrium with the other sulfides at pentlandite-pyrrhotite boundaries. Multiple sulfur isotope data were acquired from four $5 \mathrm{~mm}$ in diameter pucks of ore and values for $\delta^{34} S, \Delta^{33} S, \Delta^{36} S$ are presented in Table 4. WDS data were also acquired from the pentlandite and pyrrhotite to ensure similar chemical composition to the reference material.
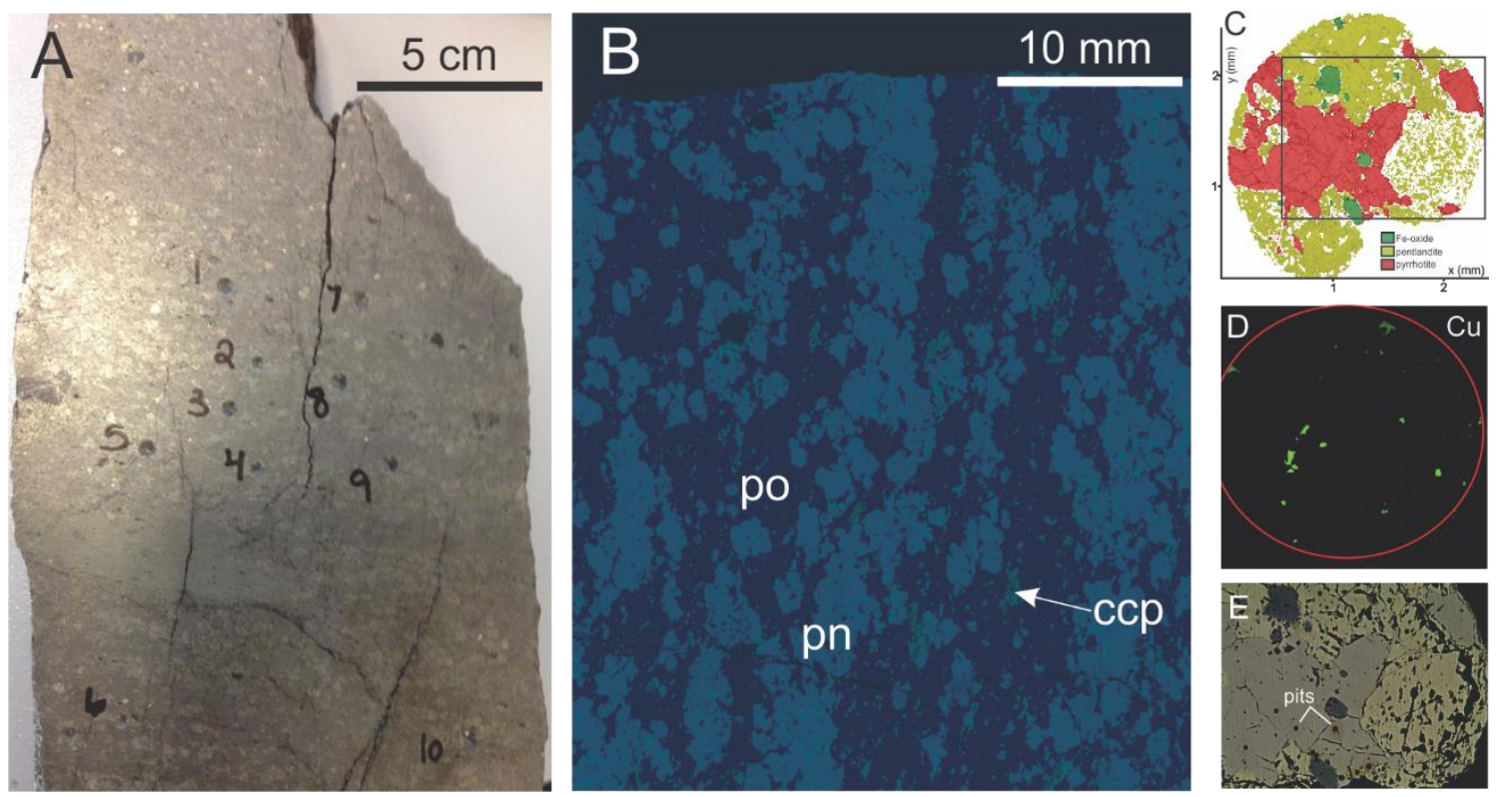

Figure 7: A) Hand sample of the Moran Shoot massive sulfide horizon of the Long-Victor deposit, Kambalda camp. Numbers demarcate localities drilled for bulk analysis. B) Micro-XRF map of slab of nickel-sulfide ore from the Moran shoot, Long-Victor deposit, Kambalda camp. Massive sulfide is composed dominantly of pentlandite (light blue) and pyrrhotite (dark blue) with minor chalcopyrite (green). The proportion of sulfides is calculated from the Micro-XRF map to be $38 \%$ pentlandite (pn), $58 \%$ pyrrhotite (po), and $4 \%$ chalcopyrite (ccp). C) EDS phase map showing distribution of $\mathrm{NiS}$ (pentlandite; yellow), $\mathrm{FeS}$ (pyrrhotite; red), and $\mathrm{FeO}$ (iron oxide; green). D) EDS Cu map showing chalcopyrite in green. E) Reflected light photomicrograph of pentlandite (yellow)-pyrrhotite (grey) association with small interstitial grains of chalcopyrite (orange). Area delineated by black box in C. Ion probe pits are small black boxes and are $15 \mu \mathrm{m}$ in length.

Table 4: Multiple sulfur isotope results $\left(\delta^{34} \mathrm{~S}_{\mathrm{V}-\mathrm{CDT}}, \Delta^{33} \mathrm{~S}_{\mathrm{V}-\mathrm{CDT}}, \Delta^{36} \mathrm{~S}_{\mathrm{V}-\mathrm{CDT}}\right)$ acquired by SIMS using reference material presented in this manuscript to correct for instrumental mass fractionation. " $n$ " is the number of measurements.

\begin{tabular}{|c|c|c|c|c|c|c|c|c|}
\hline & $\begin{array}{c}\text { Chemical } \\
\text { composition }\end{array}$ & \multicolumn{7}{|c|}{ Sulfur isotope composition (\%o) } \\
\hline & & $\delta^{34} \mathrm{~S}$ & $2 \mathrm{SD}$ & $\Delta^{33} \mathrm{~S}$ & $2 \mathrm{SD}$ & $\Delta^{36} \mathrm{~S}$ & $2 \mathrm{SD}$ & $n$ \\
\hline pentlandite & $\mathrm{Fe}_{4.1} \mathrm{Ni}_{4.8} \mathrm{Co}_{0.1} \mathrm{~S}_{8}$ & 2.91 & 0.35 & 0.25 & 0.10 & -0.03 & 0.40 & 73 \\
\hline pyrrhotite & $\mathrm{Fe}_{0.90} \mathrm{~S}$ & 3.90 & 0.20 & 0.26 & 0.13 & -0.01 & 0.24 & 19 \\
\hline chalcopyrite & $\mathrm{CuFeS}_{2}$ & 3.10 & 0.54 & 0.16 & 0.08 & -0.04 & 0.21 & 13 \\
\hline
\end{tabular}

The in situ SIMS data presented in Table 4 compare well with 10 aliquots of bulk sulfide material from the same ore shoot, which returned $\delta^{34} \mathrm{~S}_{\mathrm{V}-\mathrm{CDT}}, \Delta^{33} \mathrm{~S}_{\mathrm{V}-\mathrm{CDT}}, \Delta^{36} \mathrm{~S}_{\mathrm{V}-\mathrm{CDT}}$ equal to 
$13.10 \pm 0.70 \%$ ( $2 \mathrm{SD}$ ), $0.24 \pm 0.04 \%$ ( $2 \mathrm{SD}$ ), and $-0.21 \pm 0.10 \%_{0}$ (2SD). The large uncertainty 2 on $\delta^{34} \mathrm{~S}$ in the bulk data demonstrates that the yielded sulfur isotope results represent an 3 average isotopic composition of the three sulfide phases (as depicted by the SIMS $\delta^{34} S$ 4 results).

The case study is aimed at emphasizing the significance of a multi-sulfide phase in situ analytical approach in the determination of the multiple sulfur isotope signature of Archean komatiite-hosted nickel-sulfide deposits. Results indicate that the magmatic sulfide assemblage of the massive sulfide horizon hosted in the Moran shoot of the Long-Victor deposit in the Kambalda region of Western Australia comprises pentlandite, pyrrhotite and chalcopyrite. These phases are in isotopic equilibrium and display similar values for $\Delta^{33} \mathrm{~S}=$ $\sim+0.2 \%$ and $\Delta^{36} \mathrm{~S}=\sim-0.02 \%$. However, the three sulfide phases show variable $\delta^{34} \mathrm{~S}$ values $\left(\delta^{34} S_{\text {pentlandite }}=\sim 2.9 \%\right.$, $\delta^{34} S_{\text {chalcopyrite }}=\sim 3.1 \%$, and $\delta^{34} S_{\text {pyrrhotite }}=\sim 3.9 \%$ o $)$, which are indicative of natural isotope fractionation. Natural $\delta^{34} \mathrm{~S}$ fractionation among the sulfides that make up a multi-sulfide phase ore assemblage cannot be easily resolved through bulk rock analysis (as presented in Figure 8). This in turn may lead to misinterpretations of subtle sulfur isotope variations. In situ analysis also has the potential to highlight the presence of secondary sulfides. Therefore, the in situ approach provides the user the ability to resolve ambiguities that may arise through whole-rock isotope analysis.

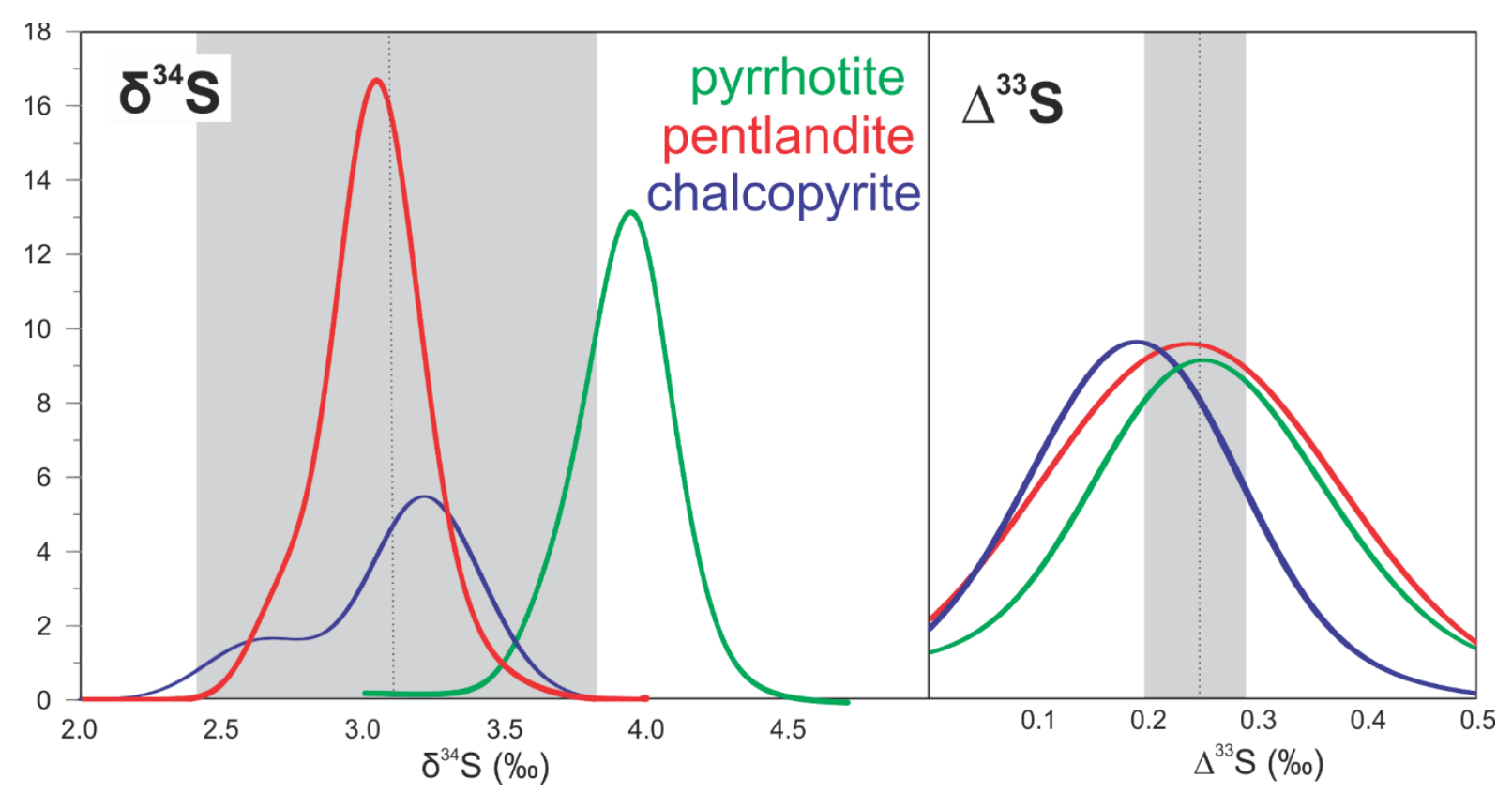

Figure 8: Probability density plots (bin size 10) of $\delta^{34} S$ and $\Delta^{33} S$ pyrrhotite, pentlandite, and chalcopyrite results for the Moran shoot of the Long-Victor deposit, Kambalda. A representative subset of pentlandite results are chosen. All three sulfide phases yield the same $\Delta^{33} S$ values $(+0.2 \%$ ) demonstrating they are likely cogenetic and from the same source. The variable $\delta^{34} \mathrm{~S}$ are a result of natural isotopic fractionation between the three sulfide phases (of which pentlandite and pyrrhotite compose $96 \%$ of the ore body). Variability in $\delta^{34} S$ chalcopyrite is a product of few analyses (13) of small interstitial grains. Whole rock bulk fluorination values (from 10 aliquots) depicted by dashed line and uncertainty (2SD) by grey box.

\subsubsection{Source of sulfur to trigger sulfide saturation}


1 The multiple sulfur isotope data collected from the Moran shoot is assessed in conjunction with the multiple sulfur isotope signature of VMSO, which was collected from the Victor

3 South shoot. Bekker et al. (2009) originally measured the multiple sulfur isotope signature of 4 the ore sample from which the VMSO pentlandite standard was made. The bulk rock fluorination data indicated that the massive sulfide in the Victor South shoot did not display any evidence of MIF. This result was not discussed in detail in Bekker et al. (2009), but it clearly portrayed Kambalda as being radically different from the giant komatiite-hosted deposits in the northern part of the Kalgoorlie Terrane, which display a very pronounced negative MIF signature (up to $-0.7 \%$ ). The bulk rock isotope signature of the VMSO ore sample is reflected in the lack of MIF recorded in the VMSO pentlandite standard presented in this study.

In the Long-Victor deposit, the relationship between the Victor South and Moran shoots is described in Barnes et al. (2013). For the sake of the argument here, the most important message to be taken away from the study of Barnes et al. (2013) is that different shoots, which originated from the emplacement of komatiite magma along spatially close but distinct volcanic channels, may have resulted from the equilibration of variable proportions of sulfide and silicate liquids. Evidence of this variable proportion, which is expressed as R Factor (Campbell and Naldrett, 1979), is not only recorded in the highly variable metal tenor of the ore shoots and associated variable degrees of chalcophile element enrichment and depletion in the host komatiite channelized units, but it is also preserved in the sulfur isotopic architecture of the deposit, as discussed in Lesher and Burnham (2001) and Fiorentini et al. (2012a). This should serve as a word of caution for any exploration targeting tool based on sulfur isotope analysis to track crustal assimilation as a proxy for magma fertility.

Evidence of a positive MIF anomaly $\left(\Delta^{33} \mathrm{~S}=0.2 \%\right.$ ) recorded in three sulfide phases of the Moran shoot suggests thermo-mechanical assimilation of sulfidic shales $\left(\Delta^{33} \mathrm{~S}=\right.$ up to $0.8 \%$; Bekker et al., 2009) during komatiite emplacement. The magnitude of MIF as expressed by $\Delta^{33} \mathrm{~S}$ is small and so to relate the sulfur isotope signature to photochemical reactions related to an oxygen-poor atmosphere (rather than mass dependent processes as described by Johnston, 2011), we evaluate the $\Delta^{36} \mathrm{~S} / \Delta^{33} \mathrm{~S}$ relationship. The $\Delta^{36} \mathrm{~S} / \Delta^{33} \mathrm{~S}$ ratio ranges from -0.04 to -0.88 , extending the known Archean ratio beyond -1 to -2 of Johnston (2011). The ratio is significantly different to the predicted range of mass dependent fractionation processes $\left(\Delta^{36} \mathrm{~S} / \Delta^{33} \mathrm{~S}=-9\right.$ to -7 ; Ono et al., 2006b; Johnston et al., 2007).

The lack of any MIF anomaly in the Victor South shoot suggests higher R factor values for the channel, which was effectively flushed with higher volumes of mantle-derived silicate magma carrying no MIF anomaly, thus diluting any evidence of crustal MIF. However, it is crucial to state that in magmatic systems, near-zero $\delta^{34} \mathrm{~S}$ or $\Delta^{33} \mathrm{~S}$ values permit a mantle source $\left(\delta^{34} S=-1.28 \pm 0.33 \% ; \Delta^{33} S=0.00 \%\right.$; Labidi et al., 2013) but do not prove it if the full complexity of homogenization processes is considered. However, non-zero $\delta^{34} S$ or $\Delta^{33} S$ values prove a non-mantle source and can be further confirmed by the $\Delta^{36} \mathrm{~S} / \Delta^{33} \mathrm{~S}$ ratio (Farquhar et al., 2007; Johnston, 2011). The data from two different shoots at Kambalda highlight the variation that characterizes ore-forming processes in magmatic systems. This 
1 variation is translated downstream in the complexity of the interpretation of chemical and isotopic data that are used as proxies to target mineralisation in exploration (Fiorentini et al., 2012a).

In addition to the deposit-scale observations discussed above, the in situ multiple sulfur isotope data presented in this study also provide key insights into the geodynamic setting where the Kambalda komatiites were emplaced. Unlike the giant dunite-hosted komatiite systems that thermo-mechanically assimilated volcanogenic massive sulfides proximal to vents in the Agnew-Wiluna greenstone belt (cf. Fiorentini et al., 2012b), the integrated results from both the Moran (case study) and Victor South (VMSO sample) shoots indicate that Kambalda ores assimilated abyssal sulfidic shales. This inference is based on the very different MIF signatures that are observed: the dunite-hosted systems in the northern Kalgoorlie Terrane (Fiorentini et al 2012b) and elsewhere globally (e.g., Heggie et al., 2012a, b) commonly display negative $\Delta^{33} \mathrm{~S}$ values (up to $-1.0 \%$ ), whereas Kambalda-style channelized systems either display no MIF or positive (up to $+1.1 \%$ ) signatures. These variable inter-shoot isotopic results at Kambalda are reflected in the variable platinum group element signature of the various channelized systems (Barnes et al., 2013). At the broader scale, these data support the hypothesis that dunite-hosted systems are generally characterized by lower R factors, where evidence of crustal contamination from proximal volcanogenic massive sulfides is preserved, in contrast to Kambalda-type deposits where evidence of crustal contamination by sulfidic shales is partially to completely erased due to extreme magma flux along channelized environments.

\subsubsection{In situ data to identify natural fractionation between pentlandite-pyrrhotite}

The complex sulfide mineralogy hosted in any mineralized sample may document various stages of the ore forming process. However, even when sulfide phases are cogenetic and in equilibrium, natural isotopic fractionation between sulfide pairs may occur due to crystal structure, temperature of formation, and chemical composition (e.g., O'Neil, 1986). For instance, the speciation of the sulfur source and the mass of a metal speciation can affect the preference for ${ }^{34} \mathrm{~S}$ incorporation in one sulfide over another during precipitation (Bachinski, 1969; Seal, 2006 and references therein). This means that the isotopic signature of a single sulfide phase hosted in a sulfide layer may not be representative of the true isotopic composition of that very horizon.

Although, fractionation of sulfur isotopes between cogenetic sulfide minerals has been investigated by Bachinski (1969), Li and Lui (2006), Ohmoto and Rye (1979), Seal (2006), among others, the natural isotope fractionation of sulfur isotopes between pentlandite and pyrrhotite has not yet been quantified; however it is an important element in the study of magmatic ore deposits. In the case study focussed on the Moran shoot of the Long-Victor deposit, if we interpret pyrrhotite and pentlandite to be in equilibrium we conclude that pyrrhotite has a natural affinity for ${ }^{34} \mathrm{~S}$ over pentlandite. Our results that demonstrate enrichment in $\delta^{34} \mathrm{~S}$ in pyrrhotite over chalcopyrite are in agreement with Li and Lui (2006). This same trend is also described for VMSO pentlandite above (also derived from a 
1 magmatic ore deposit) and has been observed in other magmatic ore deposits (LaFlamme,

2 unpublished data).

3

4

Multiple sulfur isotope analysis of massive sulfide from the Moran shoot at Long-Victor deposit yields $\delta^{34}$ S pentlandite $=2.91 \pm 0.35 \%$ o $(n=73)$ and $\delta^{34}$ S pyrrhotite $=3.90 \pm 0.20 \%$ $(n=19)$. These two phases make up $>96 \%$ of sulfides in this ore body and are within error of the bulk fluorination results $\left(\delta^{34} \mathrm{~S}=3.10 \pm 0.70 \% ; n=10\right)$. Multiple sulfur isotope analysis of the massive sulfide horizon at the Victor South shoot (from which VMSO reference material is derived) yields $\delta^{34} \mathrm{~S}$ pentlandite (measured as bulk fluorination value and incorporates a minor component of unavoidable pyrrhotite $)=3.22 \pm 0.51 \%$ o $(n=11)$ and $\delta^{34}$ S pyrrhotite (normalized to Alexo pyrrhotite $)=3.86 \pm 0.18 \%$ o $(n=7)$. This is a circular problem because it is impossible to get a true value for pentlandite unaccompanied by pyrrhotite for VMSO, and the values for in situ analyses from the Moran shoot rely on a correction for instrumental mass fractionation normalised to the VMSO reference material. Here though, we assume the cogenetic sulfides from both shoots are in natural equilibrium, and so we can broadly estimate $\delta^{34} \mathrm{~S}_{\text {pyrrhotite-pentlandite }}$ to be $0.7-1.0 \pm 0.5 \%$. The natural equilibrium isotopic fractionation between pyrrhotite and chalcopyrite determined at the Moran shoot to be $\delta^{34} \mathrm{~S}=$ $\sim 0.2 \%$, is in agreement with that defined by Li and Lui (2006). Therefore, in ore bodies with multiple sulfide phases in equilibrium, $\delta^{34} \mathrm{~S}$ values are a reflection of the relative proportions of those phases. Therefore, care should be applied when small deviations in isotopic signatures derived from bulk analyses of massive sulfide bodies are used to interpret variations in the source of sulfur, volatiles and metals in ore bodies (e.g., Bekker et al., 2009; Fiorentini et al., 2012b; Li et al., 2009). In fact, these variations may solely be reflecting proportional differences of sulfide phases, or may homogenise different phases of mineralisation with different isotopic signatures. In turn this can lead to a better understanding of small spatial and temporal changes in multiple sulfur isotopes related to the magmatic and/or hydrothermal environment.

\subsubsection{Test for potential crystallographic orientation effects in pentlandite}

The integration of EBSD with high-spatial resolution isotopic analyses allows the potential role of crystal orientation on isotopic data quality to be assessed (Taylor et al., 2012). The potential effects of grain orientation on sulfur isotope measurements in the Moran Shoot pentlandite have been assessed by comparison of EBSD-derived crystal orientation information with sulfur isotope data (as $\delta^{34} S$ and $\Delta^{33} S$ ) from known ion probe analysis sites. Results demonstrate that no orientation effect on $\delta^{34} S$ and $\Delta^{33} S$ exists for pentlandite (Figure 7). Inverse pole figures (of which one sample is shown in Figure 9) relate count rates to grain orientation in which analyses are plotted based on the angular relationship between the mount $\mathrm{x}$-direction and the main crystal axes. Comparison of grain orientation data from $\sim 50$ pentlandite grains and 73 multiple sulfur isotopes analyses demonstrates a consistent value of $\delta^{34} \mathrm{~S}$ and $\Delta^{33} \mathrm{~S}$, within the envelope of single analysis uncertainty irrespective of grain orientation.

Certain sulfide minerals (galena and sphalerite) have been shown to exhibit a crystal orientation effect resulting in instrumental mass bias towards ${ }^{34} \mathrm{~S}$, while others (pyrite, 
1 pyrrhotite and chalcopyrite) do not (Kozdon et al., 2010; Kita et al., 2011). Here, our data 2 indicate that there is no resolvable crystallographic orientation control on either $\delta^{34} \mathrm{~S}$ or $\Delta^{33} \mathrm{~S}$ 3 due to the interaction of the beam with the pentlandite grain. This is a completely new
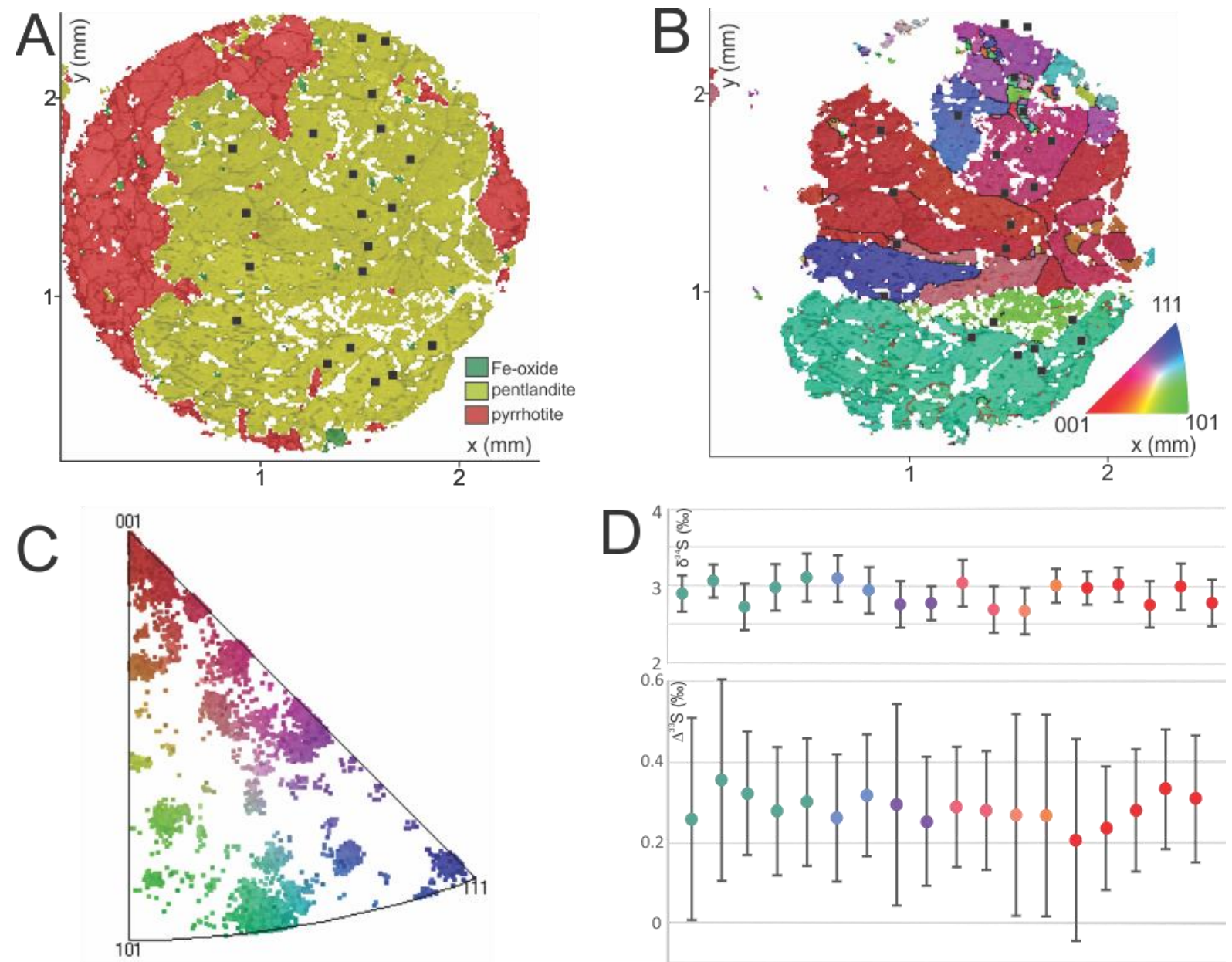

$\mathrm{D}$
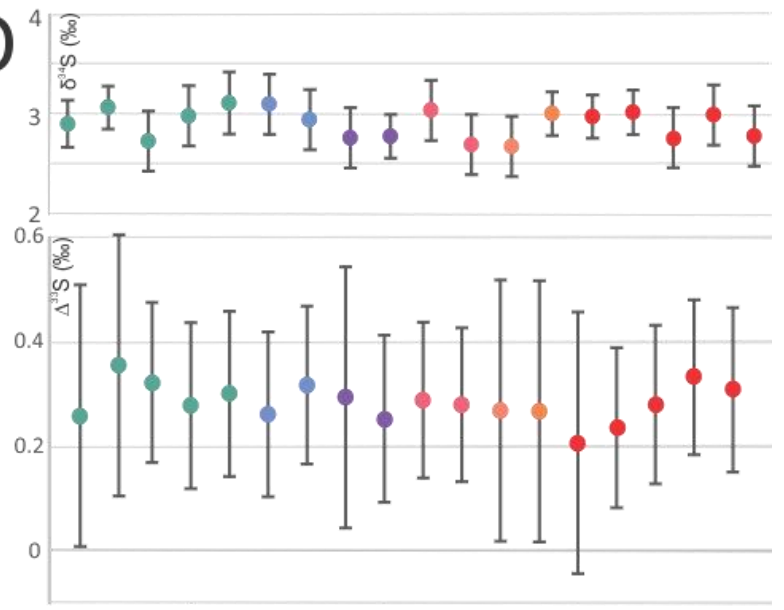

Figure 9: Example of orientation effect in pentlandite analysed by electron backscatter diffraction (EBSD).

Pentlandite from massive sulfide lens mounted as pucks (1 puck shown here) drilled from a massive sulfide lens at the Moran shoot, Kambalda. A: EDS phase map showing distribution of NiS (pentlandite; yellow), FeS (pyrrhotite; red), and $\mathrm{FeO}$ (iron oxide; green). B: Inverse pole figure map, plotted with respect to the userdefined $\mathrm{x}$ direction. Black lines show grain boundaries with $>10^{\circ}$ misorientation. $\mathrm{C}$ : Inverse pole figure (lower hemisphere equal area projection) for the sample $\mathrm{x}$ direction showing grain orientations indicated by colours of pentlandite grains shown in B ( $n=17195$ data points). D: $\delta^{34} S$ and $\Delta^{33} S$ from pentlandite with colour matched to crystallographic orientation shown in B and C.

\section{CONCLUSIONS}

Instrumental mass fractionation is dependent on the chemical matrix of the material being analysed (the so-called matrix effect). For different sulfide minerals, the matrix effect is likely due to a combination of factors including varying sulfur contents, varying cation compositions and different crystallographic systems, giving rise to different ionisation potentials and different sputtering rates (e.g., Kozdon et al., 2010). The matrix effect between conjugate pyrite-sulfide pairs is a complex problem (at least partly) related to the presence of multiple and subtle instrument conditions and analytical protocols. Hence, SIMS inter- 
1 mineral fractionation factors (even within a single laboratory) to calculate sulfur isotope ratios should be used with caution and only as a last resort. Multiple sulfur isotope studies should also take caution against propagating $\delta^{33} S$ and $\delta^{36} \mathrm{~S}$ from $\delta^{34} \mathrm{~S}$ following the mass dependent fractionation relationship for reference materials in which these values have not been quantified. It has been shown that $\Delta^{33} \mathrm{~S}$ and $\Delta^{36} \mathrm{~S}$ anomalies can occur in a range of environments even outside of Archean terranes (i.e., at Proterozoic craton margins, Selvaraja et al., 2016; this study (Proterozoic Nifty-b chalcopyrite reference material); LaFlamme, unpublished data, at modern hydrothermal vents; Ono et al., 2006b; Farquhar et al., 2007; and in other environments, Cabral et al., 2013). Therefore, for the reasons above, unknown sulfur isotope analyses should be normalised to chemically and isotopically characterised reference material, four sulfides of which are presented here.

At the Long-Victor nickel-sulfide deposit in the world class Kambalda nickel camp in the southern Kalgoorlie Terrane of Western Australia, a case study demonstrates how precise multiple sulfur isotope analyses from magmatic pentlandite, pyrrhotite and chalcopyrite can better constrain genetic models related to ore-forming processes. Results indicate that pentlandite, pyrrhotite and chalcopyrite are in isotopic equilibrium and yield the same value for $\Delta^{33} \mathrm{~S}(+0.2 \%)$. The three magmatic phases show variable $\delta^{34} \mathrm{~S}$ values $\left(\delta^{34} \mathrm{~S}_{\text {chalcopyrite }}=\right.$ $2.9 \%$, $\delta^{34} S_{\text {pentlandite }}=3.1 \%$, and $\delta^{34} S_{\text {pyrrhotite }}=3.9 \%$ ), which are indicative of natural fractionation. The results indicate that unlike the giant dunite-hosted komatiite systems that thermo-mechanically assimilated volcanogenic massive sulfides proximal to vents and display negative $\Delta^{33} \mathrm{~S}$ values, the Kambalda ores formed in relatively distal environments assimilating abyssal sulfidic shales. Careful in situ analysis is able to image the subtle isotopic variability of the magmatic sulfide assemblage, which may help resolve the nature of the ore-forming process. This approach may help to discriminate the magmatic sulfur isotope signature from that recorded in metamorphic- and alteration-related sulfides, which may not be resolved during bulk rock fluorination analysis.

\section{ACKNOWLEDGEMENTS}

30 This manuscript benefited greatly from suggestions made by Drs. Richard Stern, John Valley and two anonymous reviewers. The authors thank Klaus Mezger for editorial handling. The authors acknowledge the facilities and technical assistance of the Australian Microscopy and Microanalysis Research Facility at the CMCA, UWA and also acknowledge the facilities of the Advanced Resource Characterisation Facility at the Commonwealth Scientific and Industrial Resource Organisation and the technical assistance of Michael Verrall. Crystal LaFlamme acknowledges support from the Minerals Research Institute of Western Australia, Science and Industry Endowment Fund and Geological Survey of Western Australia. Marco Fiorentini acknowledges support from the Australian Research Council through Linkage Project LP120100668, the Future Fellowship Scheme (FT110100241), and the ARC Centre

40 for Excellence for Core to Crust Fluid Systems (CE11E0070). David Wacey acknowledges 41 support from the European Commission and the Australian Research Council through the 42 Future Fellowship Scheme (FT140100321). The Stable Isotope Laboratory in the Earth and 43 Planetary Science department at McGill University is supported by the FQRNT through the GEOTOP research centre. Early developmental work was completed by John Cliff. Materials 
1 to test in the preliminary stages of standard development were provided by Alex Bevan at the

2 Museum of Western Australia. Two reference materials were supplied by Martin Whitehouse

3 from the Nordsim laboratory and John Craven from the Edinburgh Ion Microprobe Facility.

4 This is contribution 847 from the ARC Centre of Excellence for Core to Crust Fluid Systems.

5 http://www.ccfs.mq.edu.au.

6

\section{LIST OF FIGURES}

8 Figure 1: Calculated magnitudes of mass independent fractionation as deviations from the

9 mass dependent fractionation line (MDF) presented in $\delta^{33} \mathrm{~S} v \mathrm{vs} . \delta^{34} \mathrm{~S}$ space. The small

10 deviations from the MDF line may represent mass independent fractionation. This highlights

11 the importance of: 1) precise and accurate multiple sulfur isotope measurements, and 2)

12 quantification of uncertainty on $\Delta^{33} \mathrm{~S}$. Although not expressed in this figure, quantifying $\Delta^{36} \mathrm{~S}$

13 is equally important.

15 Figure 2: Demonstration of compositional homogeneity of: A) Sierra pyrite (Fe wt.\%), B)

16 Nifty-b chalcopyrite (Cu wt.\%), C) Alexo pyrrhotite (Fe wt.\%), D) VMSO pentlandite (Ni

17 wt.\%). Wavelength dispersive spectrometry maps are collected by EPMA.

Figure 3: Probability density plots for $\delta^{34} \mathrm{~S}$ for normalized reference material to demonstrate the low degree of uncertainty, normal distribution and lack of outliers.

Figure 4: Example of compositionally homogeneous area of Alexo pyrrhotite compared to areas of significant pentlandite exsolution. Raster spots show examples of assessment of two different areas of the grain to determine effect on instrumental mass fractionation.

Figure 5: Plots of: (a) $\delta^{33} S_{\text {V-CDT Vs. }} \delta^{34} S_{\text {V-CDT }}$ and (b) $\Delta^{33} S$ vs. $\delta^{34} S_{\text {V-CDT }}$ for all sulfide reference material (Sierra pyrite, Nifty-b chalcopyrite, Alexo pyrrhotite, and VMSO pentlandite) measured by SIMS in this study. Error crosses are the overall uncertainty (at the 2SD level) based on propagating the individual analysis repeatability with the reproducibility for the relevant analytical session. The Sierra pyrite is used as the primary reference for measuring previously characterised pyrite reference material Isua 248474 and Balmat pyrite (see Whitehouse, 2013; Graham and Valley, 1992).

Figure 6: Location of the Victor-Long nickel-sulfide deposit of the Kambalda camp, Western Australia. The Victor-Long deposit is host to the Victor South and Moran shoots, discussed in this study.

Figure 7: A) Hand sample of the Moran Shoot massive sulfide horizon of the Long-Victor deposit, Kambalda camp. B) Micro-XRF map of slab of nickel-sulfide ore from the Moran shoot, Long-Victor deposit, Kambalda camp. Massive sulfide is composed dominantly of pentlandite (light blue) and pyrrhotite (dark blue) with minor chalcopyrite (green). The 42 proportion of sulfides is calculated from the micro-XRF map to be $38 \%$ pentlandite, $58 \%$ 43 pyrrhotite, and 4\% chalcopyrite. C) EDS phase map showing distribution of NiS (pentlandite; 
1 yellow), $\mathrm{FeS}$ (pyrrhotite; red), and $\mathrm{FeO}$ (iron oxide; green). D) EDS Cu map showing

2 chalcopyrite in green. E) Reflected light photomicrograph of pentlandite (yellow)-pyrrhotite

3 (grey) association with small interstitial grains of chalcopyrite (orange). Ion probe pits are

4 small black boxes and are $15 \mu \mathrm{m}$ in length.

5

6 Figure 8: Probability density plots (bin size 10 ) of $\delta^{34} S$ and $\Delta^{33} S$ pyrrhotite, pentlandite, and

chalcopyrite results for the Moran shoot of the Long-Victor Deposit, Kambalda. A representative subset of pentlandite results are chosen. All three sulfide phases yield the same $\Delta^{33} \mathrm{~S}$ values $(+0.2 \%$ ) meaning they are cogenetic and from the same source. The variable $\delta^{34} \mathrm{~S}$ are a result of natural isotopic fractionation between the three sulfide phases (of which pentlandite and pyrrhotite composed $>96 \%$ of the ore body). Whole rock bulk fluorination values (from 10 aliquots) depicted by dashed line and uncertainty (2SD) by grey box.

Figure 9 Example of orientation effect in pentlandite analysed by electron backscatter diffraction (EBSD). Pentlandite mounted as a puck drilled from a massive sulfide lens at Kambalda. A: Phases of massive sulfide as defined by electron dispersive spectrometry as $\mathrm{NiS}$ (pentlandite; light green), FeS (pyrrhotite; red), and FeO (iron oxide; dark green). B: Inverse Pole Figure with respect to the $\mathrm{x}$ direction. Black lines demonstrate more than $10^{\circ}$ misorientation which are interpreted as grain boundaries. C: Inverse Pole Figure diagram for the $\mathrm{x}$ direction (17195 data points) as equal area projection in the lower hemisphere. $\mathrm{D}: \delta^{34} \mathrm{~S}$ and $\Delta^{33} \mathrm{~S}$ from pentlandite with colour matched to crystallographic orientation demonstrating no orientation effect with respect to crystallographic orientation.

\section{REFERENCES}

Alsen, N.1925. Roentgenographische Untersuchungen der Kristallstrukturen von Magnetkies, Breithaupit, Pendlandit, Millerir und verwandten Verbindungen. Geologiska Foereningens i Stockholm Foerhandlingar 47, 19-73.

Anderson, B.R., Gemmell, J.B., Berry, R. 2001. The geology of the Nifty Copper Deposit, Throssel Group, Western Australia: Implications for ore genesis. Econ. Geol., 96, 1525-1565.

Barra, F., Valencia, V.A. 2014. Late Cretaceous porphyry copper mineralizaion in Sonora, Mexico: Implications for the evolution of the Southwest North America porphyry copper province. Mineral. Dep. 49, 879-884.

Bachinski, D.J., 1969. Bond strength and sulfur isotopic fractionation in coexisting sulfides. Econ. Geol., 64, 56-65.

Barnes, S.J., Heggie, G.J., Fiorentini, M.L. 2013. Spatial variation in platinum group element concentrations in ore-bearing komatiite at the Long-Victor deposit, Kambalda dome, Western Australia: enlarging the footprint of nickel sulfide orebodies. Econ. Geol., 108, 913-933.

Baublys, K.A., Golding, S.D., Young, E., Kamber, B.S. 2004. Simultaneous determination of $\delta^{33} \mathrm{~S}_{\mathrm{V}-\mathrm{CDT}}$ and $\delta^{34} \mathrm{~S}_{\mathrm{V}-\mathrm{CDT}}$ using masses 48,49 and 50 on a continuous flow isotope ratio mass spectrometer. Rapid Commun. Mass Spectrom., 18, 2765-2769. 
1 Bekker, A., Barley, M.E., Fiorentini, M., Rouxel, O.J., Rumble, D., Beresford, S.W. 2009.

2 Atmospheric sulfur in Archean komatiite-hosted nickel deposits. Sci., 326, 1086-1089.

3 Bühn, B., Santos, R.V., Dardenne, M.A., de Oliveira, C.G. 2012. Mass-dependent and mass4 independent sulfur isotope fractionation ( $834 \mathrm{~S}$ and $833 \mathrm{~S}$ ) from Brazilian Archean and

5 Proterozoic sulfide deposits by laser ablation multi-collector ICP-MS. Chem. Geol., 312,

$6 \quad 163-176$.

7 Campbell, I.H., Naldrett, A.J. 1979. The influence of silicate:sulfide ratios on the

8 geochemistry of magmatic sulfides. Econ. Geol., 74, 1503-1506.

9 Cabral, R.A., Jackson, M.G., Rose-Koga, E.F., Koga, K.T., Whitehouse, M.J., Antonelli,

10 M.A., Farquhar, J., Day, J.M.D., Hauri, E.H. 2013. Anomalous sulphur isotopes in plume

11 lavas reveal deep mantle storage of Archaean crust. Nat., 496, 490-494.

12 Canfield, D.E., Raiswell, R., Westrich, J.T., Reaves, C.M., Berner, R.A. 1986. The use of

13 chromium reduction in the analysis of reduced inorganic sulfur in sediments and shales.

14 Chem. Geol., 52, 149-155.

15 Chang, Z., Large, R.R., Maslennikov, V. 2008. Sulfur isotopes in sediment-hosted orogenic 16 gold deposits: Evidence for an early timing and a seawater sulfur source. Geol., 43, 971-974.

17 Chen, M., Campbell, I.H., Xue, Y., Tian, W., Ireland, T.R., Holden, P., Cas, R.A.F., Hayman, 18 P.C., Das, R. 2015. Multiple sulfur isotope analyses support a magmatic model for the 19 volcanogenic massive sulfide deposits of the Teutonic Bore Volcanic Complex, Yilgarn 20 Craton, Western Australia. Econ. Geol., 110, 1411-1423.

21 Craddock, P.R., Rouxel, O.J., Ball, L.A., Bach, W. 2008. Sulfur isotope measurement of sulfate and sulfide by high-resolution MC-ICP-MS. Chem. Geol., 253, 102-113.

Crowe, D.E., Valley, J.W., Baker, K.L. (1990). Micro-analysis of sulfur-isotope ratios and zonation by laser microprobe. Geochimi. Cosmochim. Acta, 54, 2075-2092.

Ding, T., Valkiers, S., Kipphardt, H., De Bievre, P., Taylor, P., Gonfiantini, R., Krouse, R. 2001. Calibrated sulfur isotope abundance ratios of three IAEA sulfur isotope reference materials and V-CDT with a reassessment of the atomic weight of sulfur. Geochimi.

28 Cosmochim. Acta, 65, 2433-2437.

29 Durazzo, A., Taylor, L.A. 1982. Exsolution in mss-pentlandite system: textural and genetic 30 implications for Ni-sulfide ores. Mineral. Dep., 17, 313-332.

31 Evans, K.A., Tomkins, A.G., Cliff, J., Fiorentini, M.L. 2014. Insights into subduction zone sulfur recycling from isotopic analysis of eclogite-hosted sulfides. Chem. Geol., 365, 1-19.

33 Farquhar, J., Bao, H., Thiemens, M., 2000. Atmospheric influence of Earth's earliest sulfur 34 cycle. Sci., 28, 756-758.

35 Farquhar, J., Wing, B.A. 2003. Multiple sulfur isotopes and evolution of the atmosphere. 36 Earth Planet. Sci. Lett., 213, 1-13. 
1 Farquhar, J., Johnston D. T. and Wing B. A. 2007. Implications of conservation of mass 2 effects on mass-dependent isotope fractionations: influence of network structure on sulfur 3 isotope phase space of dissimilatory sulfate reduction. Geochim. Cosmochim. Acta, 71, $4 \quad 5862-5875$.

Farquhar, J., Cliff, J., Zerkle, A.L., Kamyshny, A., Poulton, S.W., Claire, M., Adams, D., Harms, B. 2013. Pathways for Neoarchean pyrite formation constrained by mass-independent sulfur isotopes. Proc. Natl. Acad. Sci., 110, 17638-17643.

Fiorentini, M.L., Barnes, S.J., Maier, W.D., Burnham, O.M., Heggie, G.J. 2011. Global variabilitiy in the platinum-group element contents of komatiites. J. Pet., 52, 83-112.

Fiorentini, M.L., Barnes, S.J., Lesher, C.M., Heggie, G.J., Keays, R.R., Bernham, O.M. 2010. Platinum group element geochemistry of mineralized and non-mineralized komatiites and basalt. Econ. Geol., 105, 795-823.

Fiorentini M.L., Bekker, A., Rouxel, O., Wing, B.A., Maier, W., Rumble, D. 2012a. Multiple sulfur and iron isotope composition of magmatic Ni-Cu-(PGE) sulfide mineralization from Eastern Botswana. Econ. Geol., 107, 105-116.

Fiorentini, M.L., Beresford, S., Barley, M., Duuring, P., Bekker, A., Rosengren, N., Cas, R., Hronsky, J. 2012b. District to camp controls on the genesis of komatiite-hosted nickel sulfide deposits, Agnew-Wiluna greenstone belt, Western Australia: Insights from the multiple sulfur isotopes. Econ. Geol., 107, 781-796.

Giacometti, F., Evans, K., Rebay, G., Cliff, J., Tomkins, A.G., Rosetti, P., Vaggelli, G., Adams, D.T. 2014. Sulfur isotope evolution in sulfide ores from Western Alps: Assessing the influence of subduction-related metamorphism. Geochem., Geophys., Geosystems, 15, 1-22.

Graham, C.M., Valley, J.W. 1992. Sulphur isotope analysis of pyrites. Chem. Geol. - Isotope 25 Geoscience Section, 101, 169-172.

Hauri, E.H., Papineau, D., Wang, J., Hillion, F. 2016. High-precision analysis of multiple sulfur isotopes using NanoSIMS. Chem. Geol., 420, 148-161.

Heggie, G.J., Fiorentini, M.L., Barnes, S.J., Barley, M.E. 2012a. Maggie Hays Ni deposit: Part 1: Stratigraphic controls on the style of komatitte emplacement in the 2.9 Ga Lake Johnston Greenstone Belt, Yilgarn Craton, Western Australia. Econ. Geol., 107, 797-816. Heggie, G.J., Fiorentini, M.L., Barnes, S.J., Barley, M.E. 2012b. Maggie Hays Ni deposit: Part 2: Nickel mineralization and the spatial distribution of PGE ore-forming signatures in the Maggie Hays Ni System, Lake Johnston Greenstone Belt, Western Australia. Econ. Geol., $34 \quad 107,817-833$. the genesis of the Archean oxidized, intrusion-related Canadian malartic gold deposit, Quebec, Canada. Econ. Geol., 109, 713-735. 
1 Hiebert, R.S., Bekker, A., Wing, B.A., Rouxel, O.J. 2013. The role of paragneiss assimilation 2 in the origin of the Voisey's Bay Ni-Cu sulfide deposit, Labrador: Multiple $\mathrm{S}$ and Fe isotope 3 evidence. Econ. Geol., 108, 1459-1469.

4 Hulston, J.R., Thode, H.G. 1965. Variations in the S33, S34, and S36 contents of meteorites 5 and their relation to chemical and nuclear effect. J. Geophys. Res., 70, 3475-3484.

6 Jamieson, J.W., Wing, B.A., Farquhar, J., Hannington, M.D. 2013. Neoarchean seawater 7 sulphate concentrations from sulphur isotopes in massive sulphide ore. Nat. Geosci., 6, 61864.

9 Johnston, D.T., Farquhar, J., Canfield, D.E., 2007. Sulfur isotope insights into microbial sulfate reduction: when microbes meet models. Geochim. Cosmochim. Acta, 71, 3929-3947.

11 Johnston, D.T., 2011. Multiple sulfur isotopes and the evolution of Earth's surface sulfur 12 cycle. Earth-Sci. Rev., 106, 161-183.

13 Kelly, D.P., Vaughn, D.J. 1983. Pyrrhotite-pentlandite ore textures: a mechanistic approach. 14 Mineral. Mag., 47, 453-463.

15 Kita, N.T., Huberty, J.M., Kozdon, R., Beard, B.L., Valley, J.W. 2011. High precision SIMS 16 oxygen, sulfur and iron stable isotope analyses of geological materials: accuracy, surface 17 topography and crystal orientation. Surf., Interface, Anal., 43, 427-431.

18 Kozdon, R., Kita, N.T., Huberty, J.M., Fournelle, J.H., Johnson, C.A., Valley, J.W. 2010. In 19 situ sulfur isotope analysis of sulfide minerals by SIMS: Precision and accuracy, with 20 applications to thermometry of 3.5 Ga Pilbara cherts. Chem. Geol., 275, 243-253.

21 Labidi, J., Cartigny, P., Moreira, M. 2013. Non-chondritic sulphur isotope composition of the 22 terrestrial mantle. Nat., 501, 208-211.

Leach D.L., Sangster D.F., Kelley K.D., Large, R.R., Garven, G., Allen, C.R., Gutzmer, J., Walters, S.G. 2005. Sediment-hosted lead-zinc deposits: A global perspective, in: Hedenquist J.W., Thompson J.F.H., Goldfarb R.J., and Richards J.P. (Eds.), Econ. Geol. 100th Anniversary Volume, 1905-2005, pp. 561-607. Littleton, CO: Society of Economic Geologists Inc.

Lesher, C.M., Groves, D.I. 1986. Controls on the formation of komatiite-associated nickelcopper sulfide deposits, in: Friedrich, G.H. (Ed.), Geology and metallogenesis of copper deposits: Proceedings of the Twenty-Seventh International Geological Congress, Berlin, Springer Verlag, pp. 43-62.

Lesher, C.M., Burnham, O.M. 2001. Multicomponent elemental and isotopic mixing in Ni$\mathrm{Cu}-(\mathrm{PGE})$ ores at Kambalda, Western Australia. Can. Mineral., 39, 421-446.

Li, Y., Liu, J. 2006. Calculation of sulfur isotope fractionation in sulfides. Geochim. Cosmochim. Acta 70, 1789-1795. 
1 McCuaig, T.C., Beresford, S., Hronsky, J. 2010. Translating the mineral systems approach

2 into an effective exploration targeting system. Ore Geol. Rev., 38, 128-138.

3 Naldrett, A.C. 1966. The role of sulphurisation in the genesis of iron-nickel sulphide deposits

4 of the Porcupine district, Ontario. Can. Inst. Min. Metall. Trans., 69, 147-155.

5 Naldrett, A.C., Craig, J.R., Kullerud, G. 1967. The central portion of the Fe-Ni-S system and

6 its bearing on pentlandite exsolution in iron-nickel sulfide ores. Econ. Geol., 62, 826-847.

7 O'Neil, J.R. 1986. Theoretical and experimental aspects of isotopic fractionation. In: Valley,

8 J.W., Taylor, H.P., O’Neil, R. (Eds.), Stable Isotopes in High Temperature Geological

9 Processes. Mineralogical Society of America, Washington, pp. 1-40.

10 Ohmoto, H., Rye, R.O. 1979. Isotopes of sulfur and carbon, in: Barnes, H.L. (Ed.),

11 Geochemistry of Hydrothermal Ore Deposits, $2^{\text {nd }}$ edition. J Wiley and Sons, pp. 509-567.

12 Ono, S., Wing, B., Rumble, D., Farquhar, J. 2006a. High precision analysis of all four stable 13 isotopes of sulfur $\left({ }^{32} \mathrm{~S},{ }^{33} \mathrm{~S},{ }^{34} \mathrm{~S}\right.$ and $\left.{ }^{36} \mathrm{~S}\right)$ at nanomole levels using a laser fluorination isotope14 ratio-monitoring gas chromatography-mass spectrometry. Chem. Geol., 225, 30-39.

15 Ono, S., Wing B., Johnston D., Farquhar J. and Rumble D. 2006b. Mass-dependent 16 fractionation of quadruple stable sulfur isotope system as a new tracer of sulfur 17 biogeochemical cycles. Geochim. Cosmochim. Acta 70, 2238-2252.

Penniston-Dorland, S.C., Wing, B.A., Nex, P.A.M., Kinnaird, J.A., Farquhar, J., Brown, M., Sharman, E.R. 2008. Multiple sulfur isotopes reveal a magmatic origin for the Platreef platinum group element deposit, Bushveld Complex, South Africa. Geol., 36, 979-982.

Peres, P., Kita, N.T., Valley, J.W., Fernandes, F., Schuhmacher, M. 2012. New sample holder geometry for high precision isotope analyses. Surf. Interface Anal., 45, 553-556.

Rajamani, V., Prewitt, C.T. 1975. Thermal expansion of the pentlandite structure. Am. Min., $60,39-48$.

Schuhmacher, M., Fernandes, F., De Chambost, E. 2003. Achieving high reproducibility isotope ratios with the Cameca IMS 1270 in the multicollection mode. Appl. Surf. Sci., 231232, 878-882.

Seal, R.R. 2006. Sulfur isotope geochemistry of sulfide minerals. Rev. Mineral. Geochem., $30 \quad 61,633-677$.

31 Selvaraja, V., LaFlamme, C., Fiorentini, M. Wing, B., Bui, T.H. Anomalous isotope

Sharman, E.R. Penniston-Dorland, S.C., Kinnaird, J.A., Nex, P.A.M., Brown, M., Wing, B.A. 2013. Primary origin of marginal Ni-Cu-(PGE) mineralization in layered intrusions: $\triangle^{33} \mathrm{~S}$ evidence from The Platreef, Bushveld, South Africa. Econ. Geol., 108, 365-377. 
1 Shimizu, N., Hart, S.R. 1982. Applications of the ion microprobe to geochemistry and cosmochemistry. Ann. Rev. Earth Planet. Sci., 10, 483-526.

3 Stern, R.A. 2008. An introduction to secondary ion mass spectrometry (SIMS) in geology.

4 Mineralogical Association of Canada Short Course 41, 1-18.

5 Stone, W.E., Beresford, S.W., Archibald, N.J. 2005. Structural setting and shape analysis of

6 nickel sulfide shoots at the Kambalda Dome, Western Australia: implications for deformation

7 and remobilization. Econ. Geol., 100, 1441-1455.

8 Strauss, H. 1997. The isotopic composition of sedimentary sulfur through time. Palaeogeogr.,

9 Palaeoclimatology, Palaeoecol., 132, 97-118.

10 Taylor, R., Clark, C., Reddy, S.M., The effect of grain orientation on secondary ion mass

11 spectrometry (SIMS) analysis of rutile. Chem. Geol., 300, 81-87.

12 Thomassot, E., O’Neil, J., Francis, D., Cartigny, P., Wing, B. 2015. Atmospheric record in

13 the Hadean Eon from multiple sulfur isotope measurements in Nuvvuagittuq Greenstone Belt

14 (Nunavik, Quebec). Proc. Nat. Aca. Sci., 112, 707-712.

15 Ushikubo, T., Williford, K.H., Farquhar, J., Johnston, D.T., Van Kranendonk, M.J., Valley,

16 J.W. 2014. Development of in situ four-isotope analysis with multiple Faraday cup detectors

17 by SIMS and application to pyrite grains in a Paleoproterozoic glaciogenic sandstone. Chem.

18 Geol., 383, 86-99.

19 Wacey, D., Kilburn, M.R., Saunders, M., Cliff, J., and Brasier, M.D. 2011. Microfossils of

20 sulfur metabolizing cells in $~ 3.4$ billion year old rocks of Western Australia. Nat. Geosci., 4,

$21 \quad 698-702$.

22 Whitehouse, M. J., Kamber, B.S., Fedo, C.M., Lepland, A. Integrated Pb- and S-isotope

23 investigation of sulphide minerals from the early Archaean of southwest Greenland. Chem.

24 Geol., 222, 112-131.

25 Whitehouse, M., 2013. Multiple sulfur isotope determination by SIMS: Evaluation of

26 reference sulfides for $\Delta^{33} \mathrm{~S}$ with observations and a case study on the determination of $\Delta^{36} \mathrm{~S}$.

27 Geostand. Geoanal. Res., 37, 19-33.

28 Williford, K.H., Van Kranendonk, M.J., Ushikubo, T., Kozdon, R., Valley, J. 2011.

29 Constraining atmospheric oxygen and seawater sulfate concentrations during

30 Paleoproterozoic glaciation: In situ sulfur three-isotope microanalysis of pyrite from the

31 Turee Creek Group, Western Australia. Geochim. Cosmochim. Acta, 75, 5686-5705.

32 Wing, B. Farquhar, J. 2015. Sulfur isotope homogeneity of lunar mare basalts. Geochim.

33 Cosmochim. Acta, 170, 266-280.

34 Xue, Y., Campbell, I., Ireland, T. Holden, P., Armstrong, R. 2013. No mass-independent

35 sulfur isotope fractionation in auriferous fluids supports a magmatic origin for Archean gold

36 deposits. Geol., 41, 791-794. 